\title{
Militancia, facciones y juventud en el Partido Socialista Almeyda (1979-1990)
}

\author{
Militancy, factions and youth in the Almeyda Socialist Party (1979-1990)
}

\author{
Víctor Muñoz Tamayo*
}

\begin{abstract}
Resumen: El artículo analiza la historia del Partido Socialista en dictadura, focalizando en la facción mayoritaria en el interior de Chile, es decir, aquella que a partir de la división de 1979 pasa a ser el PS dirigido por Clodomiro Almeyda. Se ahonda en dos aspectos: por una parte, en los roles y el carácter que asume la militancia juvenil en el PS clandestino interior; y por otra, en el fenómeno faccional que se desarrolla al interior del propio "almeydismo". Todo ello en un marco temporal que llega hasta la unidad partidaria de 1990.
\end{abstract}

Palabras clave: Partido Socialista - Almeydismo - Faccionalismo - Juventud Socialista.

\begin{abstract}
The article analyzes the history of the Socialist Party during dictatorship, focusing on the major faction in Chile, i.e. the faction directed by Clodomiro Almeyda in 1979 after the internal division. It delves into two aspects, on the one hand the roles and character assumed by youth militancy in the inner clandestine PS, and on the other hand, in the factional phenomenon that develops within "almeydismo" itself. All this in a temporary frame until the party unit in 1990.
\end{abstract}

Keywords: Socialist Party - Almeydism - Factionalism - Socialist Youth.

Recibido: $22 / 05 / 2017$

Aceptado: 17/07/2017

\footnotetext{
* Chileno. Doctor en Estudios Latinoamericanos UNAM. Investigador Centro de Estudios de la Juventud CEJU Universidad Católica Silva Henríquez UCSH. Este trabajo se enmarca en el proyecto FONDECYT Iniciación número 11140307, tres años de duración y titulado: "Generaciones, cultura militante y faccionalismo en los partidos Socialista y Demócrata Cristiano de Chile. Cambios contemporáneos en las nociones de "la política", "el partido" y su vinculación con la sociedad. 1973 - 2015”, UCSH. vmunozta@gmail.com
} 
Desde su fundación en 1933, tras la corta experiencia de República Socialista liderada por Marmaduke Grove y Eugenio Matte, el Partido Socialista de Chile reunió a personas y agrupaciones militantes pre existentes de diversa identidad doctrinaria (social demócratas, marxistas, anarquistas, trotskistas, antioligarcas latinoamericanistas, entre otros) y social (sectores populares - obreros, sectores medios estudiantiles, profesionales e intelectuales). ${ }^{1}$ Desde entonces, este partido adquirió un modo de organización en donde ha sido un factor determinante la existencia de agrupamientos faccionales, ${ }^{2}$ visibles, organizados y con fuerte identidad, a partir de los cuales se ha estructurado la dinámica militante, habiendo momentos en que tales grupos y liderazgos asociados coexisten en unidad orgánica, así como otros momentos en que se autonomizan (por decisión propia o expulsiones). Así como han sido recurrentes las divisiones, también lo han sido las reunificaciones, las que, si bien atienden las heridas arrastradas desde las rupturas, dan lugar a la continuidad o emergencia de nuevas facciones.

Sin embargo, la constante de la realidad faccional no debe llevarnos a suponer su inmovilismo como lógica política, puesto que en cada proceso de rupturas y reunificaciones ha habido cambios significativos en los sentidos otorgados al faccionalismo, en el tipo de identidad que se asocia al fenómeno, y en el modo en que éste se relaciona con concepciones más amplias sobre la política y su vínculo con la sociedad.

En el presente artículo propongo el análisis de un proceso que va desde una ruptura, la de 1979, hasta una reunificación, la de 1989 -1990, focalizando en un grupo determinado y en determinadas generaciones militantes. La idea es centrarse, por un lado, en el PS que configuró la mayor facción autónoma en Chile desde el quiebre de 1979, es decir, la dirigida por el ex canciller de Salvador Allende, Clodomiro Almeyda ("PS - Almeyda"); y por otro, en las generaciones de jóvenes que socializaron como militantes en esta facción (o su estructura previa como PS mayoritario en el interior), reconstruyendo tanto el partido como su estructura juvenil (la Juventud Socialista JS).

La focalización en los "almeydistas" busca captar las lógicas políticas que desplegaron y los sentidos identitarios que desarrollaron en un contexto marcado por las diferencias en la oposición en torno a las tácticas y estrategias para la lucha contra la dictadura. Fundamentalmente, se pretende ahondar en un aspecto que puede resultar paradojal: el que siendo la corriente almeydista la heredera de lecturas leninistas que enfatizaron el ideal de una orgánica cohesionada y en lucha contra los faccionalismos, tal corriente sí tuvo facciones en su interior, algunas que quebraron con el almeydismo durante la dictadura y otras que permanecieron hasta que entraron como tendencias a la reunificación de 1990. En definitiva, el eje del presente artículo es el faccionalismo dentro de la mayor facción autonomizada de los socialistas chilenos, y el cómo, en el inicio de la

\footnotetext{
${ }^{1}$ Ver: Paul Drake, Socialismo y populismo. Chile 1936 - 1973, Valparaíso, Instituto de Historia UCV, 1992. Julio Cesar Jobet, Historia del Partido Socialista de Chile, Santiago, Documentas, 1987.

2 No existe un consenso en las ciencias sociales sobre categorías como "corrientes", "tendencias", "facciones" y "fracciones". El cientista político Giovanni Sartori, reconociendo esta situación, llama "fracción" al fenómeno general de la subdivisión partidaria, distinguiendo en ese nivel entre las "tendencias" que sugieren conjuntos establecidos de actitudes que expresan diferenciaciones poco visibles, y las "facciones" que serían grupos específicos y con alta visibilidad dentro de un partido. En este texto se hablará de faccionalismo para referirse al fenómeno general de los subgrupos partidarios internos en el PS así como a aquellas coyunturas en que se producen facciones autonomizadas producto de rupturas orgánicas. Ver: Giovanni Sartori, Partidos y sistemas de partidos, Madrid, Alianza, 2005.
} 
posdictadura, dicho faccionalismo se trasladó a un PS unificado en que el "tronco almeydista" dio origen a diferentes grupos que permanecen hasta el día de hoy.

La focalización en la militancia juvenil busca aportar al conocimiento de un tema poco tratado en el estudio histórico de las militancias: las juventudes políticas ${ }^{3}$, su rol en el desarrollo de las dinámicas internas de los partidos y la sedimentación de una cultura militante a partir de las relaciones intergeneracionales. En el caso del PS esto resulta una cuestión fundamental, primero porque la construcción de la militancia clandestina la dirigieron en gran medida cuadros jóvenes, segundo porque hubo un esfuerzo claro por reconfigurar una juventud partidista, la que llegó a tener importante visibilidad pública, particularmente en un frente social como el estudiantil, jugando, además, un rol determinado en la dinámica interna y el fenómeno faccional.

\section{La Unidad Popular, la Juventud Socialista y el faccionalismo partidario al momento del golpe de Estado}

El golpe de Estado de 1973 se produjo en un momento en que el Partido Socialista de Chile discutía intensamente qué ruta seguir para la construcción del socialismo, cómo entender el rol del gobierno y qué sentido otorgar a la movilización de masas en ese tránsito conflictivo. En tal debate, si bien hubo sectores allendistas comprometidos con la vía institucional (con apoyo de la movilización popular, pero dentro del entramado del sistema político vigente), y apostando por la confluencia y el diálogo con los sectores medios y sus referentes políticos; también existieron importantes sectores que defendieron la tesis de fortalecer un "poder popular" que desbordara la institucionalidad y preparara las condiciones para asumir una vía insurreccional armada. ${ }^{4}$ En términos de alianzas políticas, mientras los primeros tenían más afinidad con los comunistas, los segundos sintieron cercanía con las tesis que desde fuera de la Unidad Popular (UP) sustentaba el MIR.

Exequiel Ponce, Carlos Lorca y buena parte de los que asumieron la primera dirección clandestina socialista articulada al interior del país tras el golpe de Estado, habían participado en los años sesenta de La Organa, un grupo que propuso avanzar hacia formas de lucha armada que prepararan el momento de la destrucción del aparato burocrático y militar del "estado burgués" por parte de una vanguardia revolucionaria, todo ello, en el marco de las líneas estratégicas establecidas primero en el Congreso Socialista de Linares en 1965 (cuyo voto político constata la necesidad del elemento insurreccional y descarta la vía electoral como método para alcanzar el poder), ${ }^{5}$ y luego en el Congreso de Chillán de

\footnotetext{
${ }^{3}$ Sobre la Juventud Socialista ver: Jorge Valle y José Díaz, Federación de la Juventud Socialista. Apuntes históricos 1935 - 1973, Santiago de Chile, Cuadernos Documentas, 1987. Sobre otras juventudes políticas: Rolando Álvarez y Manuel Loyola (editores), Un trébol de cuatro hojas. Las Juventudes Comunistas de Chile en el siglo XX, Santiago de Chile, Ariadna, 2014. Fernando Pairicán, La gran crisis: las Juventudes Comunistas de Chile defendiendo su identidad en tiempos de transición y renovación democrática 1989 - 1992, Izquierdas número 30, IDEA - UACH, Santiago, 2016,124 -160. Víctor Muñoz Tamayo, Generaciones. Juventud universitaria e izquierdas políticas en Chile y México, Santiago de Chile, Lom, 2011.

${ }^{4}$ Joan Garcés, Allende y la experiencia chilena. Las armas de la política, Santiago de Chile, Hueders, 2013.

${ }^{5}$ Sin embargo, tal como sostiene Marcelo Casals, "estas nuevas perspectivas estratégicas no significaban, en el corto plazo, un abstencionismo radical y perpetuo, sino más bien la implementación de una orientación revolucionaria de la participación electoral, funcional al impulso de las masas a la lucha revolucionaria”. Marcelo Casals, El alba de una
} 
1967 (que otorgó a las formas violentas de lucha un carácter legítimo e inevitable en tanto "única vía que conduce a la toma del poder político y económico"). ${ }^{6}$ De hecho, fue luego de la defensa armada de la toma del fundo San Miguel en 1968, que militantes socialistas que apoyaron dicha acción fundaron La Organa. ${ }^{7}$ En 1970, esta organización se fusionó con otra orgánica creada con anterioridad: la sección chilena del boliviano Ejército de Liberación Nacional ELN (que apoyaba operativamente a dicha guerrilla, incluso con combatientes internacionalistas), de modo que se conformó una sola organización que operó como corriente al interior del partido y que fue conocida como los Elenos. ${ }^{8}$ No obstante este origen en el radicalismo guevarista, durante el gobierno de Allende los Elenos asumieron la defensa de la conducción allendista y la vía electoral, promovieron el fortalecimiento de la alianza con el PC, defendieron la idea de un partido cohesionado por vía de una orgánica leninista y, en concordancia con esto último, anunciaron su propia disolución como tendencia en enero de 1971. Pese a este anuncio, mantuvieron sus redes, operaron coordinados y promovieron a Carlos Lorca para presidir la Juventud Socialista, cuestión que se materializó en la Vigésima Conferencia Nacional de la JS celebrada en Concepción durante 1971.

El diagnóstico de la conducción de Lorca era que las luchas internas del PS se habían extendido a la Juventud, provocando faccionalismos y caudillismos en desmedro del objetivo prioritario de la lucha de masas. Se planteó que el rol formativo de la JS permitiría cambiar esas lógicas, siempre y cuando se tratase de una orgánica fuerte y autónoma respecto de las decisiones que tuvieran que ver con sus frentes de acción. De tal modo, la dirección juvenil apeló al centralismo democrático leninista como principio de subordinación de las minorías respecto a la mayoría, y remedio contra la indisciplina que representaría la lucha fraccional. ${ }^{9}$

Durante el tiempo en que los ex Elenos dirigieron la JS, el evento más recordado de la lucha de Lorca por un partido cohesionado y disciplinado, fue la fuerte tensión entre su dirección y una corriente conocida como Militantes Rojos, que dirigía el ex presidente de la federación estudiantil de la Universidad Técnica, Juan Gutiérrez Soto. ${ }^{10}$ Juan Gutiérrez había presidido la Juventud por un breve periodo durante 1968 (reemplazando interinamente a Juan Ruz), y en 1971 apareció como carta que perdió ante Lorca la presidencia de dicha orgánica. Iniciado el gobierno de Allende, los Militantes Rojos, al igual que el sector de Lorca, abogaron por un partido cohesionado y leninista ("homogéneo,

revolución. La izquierda y el proceso de construcción estratégica de la “vía chilena al socialismo”, Lom, Santiago, 2010, 136.

${ }^{6}$ Voto político emanado del Congreso de Chillán, citado en: Casals, Ibid, 179.

${ }^{7}$ Juan Azocar Valdés, Lorca. Vida de un socialista ejemplar, Santiago de Chile, Radio Universidad de Chile, 2015.

${ }^{8}$ Nombre relativo a la sigla ELN. Ver: Jorge Arrate y Eduardo Rojas, Memoria de la Izquierda Chilena, tomo dos, Javier Vergara editor, Santiago, 2003.

${ }^{9}$ En las fuentes, la dirección de la JS ocupa las palabras "fracción" y "fraccionalismo" para referirse a la lucha de grupos en un contexto de indisciplina partidaria. También son explícitas en diferenciar el término "tendencia", en tanto diversidad de opiniones, de "fracción". Esta última, se definía como ilegítima pues atentaría contra la cohesión requerida para un partido de vanguardia. Ver: "Contra el fraccionalismo y la doble militancia”. Boletín Juventud Socialista. Mayo, 1972.

${ }^{10}$ En los años 80 Juan Gutiérrez participó de corrientes socialistas moderadas, del espectro de la renovación, que se incorporaron a la Alianza Democrática. Participó primero en la llamada Convergencia 19 de abril (también mencionada como Consenso 19 de abril), luego en el PS-Mandujano que apareció en 1984 como escisión del PS Núñez-Briones, hasta que en 1985 rompió con la fracción de Mandujano y pasó a liderar otra nueva denominada PS Histórico. Ver: "Socialistas. Sus bodas y divorcios". Revista Hoy. 16 al 22 de mayo. 1984. Y “Juan Gutiérrez: área socialista, alternativa de poder". Revista Análisis, 17 al 24 de septiembre, 1985. 
disciplinado"), ${ }^{11}$ pero a diferencia de los ex Elenos, enfatizaron en la necesidad de avanzar hacia una organización político militar y un poder popular que desbordara la “institucionalidad burguesa". Al mismo tiempo, mientras los Militantes Rojos apostaron por la "necesidad de depuración", 12 apuntando como antagonista a la "social democracia" del partido, la dirección de Lorca, en nombre de la disciplina partidaria, el centralismo democrático y la lealtad socialista con el gobierno, condenó el "infantilismo revolucionario" expresado en el fenómeno fraccional. En junio de 1972, el informe de la comisión política al pleno del Comité Central de la JS era claro en tal mensaje:

"Las fracciones, por sobre su palabrería revolucionaria se constituyen en las más fieles servidoras de la contrarrevolución, al atentar contra nuestro partido, al desprestigiar y destruir la estructura partidaria, al impedir a la juventud golpear como un solo hombre a los enemigos de nuestro pueblo (...) El camino de la construcción de una Juventud socialista fuerte ligada a las masas, que impulse firmemente la línea del partido, pasa por no tener contemplaciones con la actividad fraccional." 13

Dos meses después, los Militantes Rojos fueron expulsados de la JS. ${ }^{14}$ También se dio, como una especificidad de la lucha contra el faccionalismo, el combate de la dirección juvenil socialista contra cualquier signo de doble militancia, en lo que se apuntaba principalmente a la relación de determinados grupos socialistas con el MIR: "Hay compañeros que aparte de ser socialistas, son también militantes de movimientos de extrema izquierda: MIR - MR-2, etc., que están infiltrados en el partido para captarse nuestros cuadros infundiéndoles desprecio por el Partido y llevárselos a su organización. "15 En este contexto, el golpe de Estado de 1973 ocurre en medio de un debate intenso sobre la actividad faccional, e indudablemente dicho debate trasciende hacia la dictadura, incorporando, a modo de balance, su vinculación con las razones de la derrota del proyecto de la UP.

\section{El faccionalismo socialista post golpe, la dirección clandestina interior y el quiebre de 1979}

Tras el golpe de Estado las tensiones persistieron en la clandestinidad y en el exilio, y aunque se logró construir una dirección en Chile con algunos miembros del Comité Central elegido en el Congreso de 1971, como el dirigente de los trabajadores portuarios Exequiel Ponce y el diputado y Secretario General de la Juventud Socialista Carlos Lorca, aparecieron grupos al interior del país que desconocieron a esa dirección, como la

\footnotetext{
${ }^{11}$ En: Carta de Juan Gutiérrez al Pleno de la FJS. Boletín número 1, “Militantes Rojos”. Octubre, 1970.

${ }^{12}$ Idem.

${ }^{13}$ Informe de la Comisión política al Pleno del Comité Central de la Juventud Socialista. Presentado por el Secretario General de la JS, Carlos Lorca Tobar. 4 de junio de 1972.

${ }^{14} \mathrm{El}$ que en estos años se impusiera la sigla JS por sobre la antigua denominación, Federación Juvenil Socialista FJS, se debe vincular con la perspectiva leninista de disciplina partidaria. Como se plantea en un documento de la JS: "Todas y cada una de las cosas que tenemos que hacer pasa por la necesidad urgente de contar con un partido, pero con un partido, no con una federación de grupos socialistas". "Contra el fraccionalismo y la doble militancia", op cit.

15 "Contra el fraccionalismo y la doble militancia", op cit.
} 
Coordinadora Nacional de Regionales CNR que conformó una dirección interior paralela a partir de estructuras orgánicas regionales (principalmente comités regionales Santiago Centro y Santiago Cordillera). Mientras tanto, Carlos Altamirano permanecía como Secretario General del PS en el exterior y era reconocido por la dirección interior, aunque ésta declaraba que la estructura exterior era subordinada a la dirección política ejercida desde Chile. ${ }^{16}$ De todos modos, no será sino hasta principios de 1975, en el Pleno de La Habana, que se reunirá y articulará de modo más formal un secretariado exterior con miembros del Comité Central en el exilio, existiendo, en la práctica, dos direcciones. Lo anterior será origen de permanentes tensiones, desde que ambas direcciones tomen decisiones contrapuestas, hasta que los dirigentes del interior resientan lo que a su juicio sería la tolerancia del secretariado exterior respecto a grupos que en Chile operaban como facciones autónomas. ${ }^{17}$

La mayor parte de la primera dirección clandestina fue detenida y hecha desaparecer por la dictadura entre 1974 y 1975 (Lorca, Ricardo Lagos Salinas, Víctor Zerega, Exequiel Ponce).$^{18}$ No obstante su corta duración, dejó instaladas una serie de ideas fuerza relativas a la evaluación de la derrota y los caminos a seguir que se expresaron en un texto emitido en el mes de marzo de 1974, conocido como Documento de Marzo. ${ }^{19}$ En lo evaluativo, este texto expresó dos críticas, una a las líneas más moderadas y otra a las perspectivas más radicales de la izquierda durante la UP. Sobre las primeras se diagnosticó una magnificación de las posibilidades de la vía pacífica (crítica al PC), las que no habrían considerado el carácter de clases de la institucionalidad y el enfrentamiento social que suponía todo proyecto que afectara los intereses de la burguesía. Sobre las segundas, se planteaba que un extremismo infantil pequeño burgués (crítica al MIR y a posiciones dentro del propio PS) se limitó a la verborrea insurreccionalista, sin diferenciar los enemigos principales del proyecto socialista, desechando cualquier acuerdo táctico con representantes sociopolíticos de las capas medias, y reduciendo la revolución y el problema del poder a meras situaciones de enfrentamiento. Sobre los caminos a seguir, se instaló la idea de conformar un frente amplio antifascista con hegemonía proletaria destinado a combatir el proyecto dictatorial definido como transformación mayor orientada a superexplotar la mano de obra, facilitar las importaciones e inversión extranjera, y fortalecer la concentración de la propiedad y la producción. De hecho, se sostenía que tales orientaciones del régimen harían factible una alianza amplia con los sectores más afectados de la pequeña burguesía y burguesía no monopólica, lo que implicaba asumir que la revolución socialista no sería el objetivo de esta etapa de lucha, sino la restauración y

\footnotetext{
16 "La dirección política del Partido se ejerce desde Chile y a la dirección interior de la lucha revolucionaria se subordina el trabajo del Secretariado Exterior del Partido, encabezado por el Secretario General del Partido, Camarada Carlos Altamirano". En: Dirección PS interior, "Al calor de la lucha contra el fascismo, construir la fuerza dirigente del pueblo para asegurar la victoria", marzo de 1974.

${ }^{17}$ De hecho, cuando Altamirano convocó al Pleno de Habana en 1975, se invitó también a la CNR, haciéndose gestiones para sacar de Chile a uno de sus dirigentes a fin de trasladarlo a Cuba. Ver: Fernández Joaquín, Góngora Álvaro, Arancibia Patricia. Ricardo Núñez, trayectoria de un socialista de nuestros tiempos, Santiago, Universidad Finis Terrae, 2013.

${ }^{18}$ Entre los sobrevivientes de esta dirección estuvo Gustavo Ruz y Alejandro Jiliberto. Ver Edison Ortiz, El socialismo Chileno, de Allende a Bachelet. (1973 - 2005), Santiago, Alerce Talleres Gráficos, 2007.

${ }^{19}$ Dirección PS interior, op.cit.
} 
ampliación de las conquistas sociales de los trabajadores con miras a una "democracia popular".

La impronta leninista del Documento de Marzo resultaba evidente en tres aspectos. En primer lugar, en el reclamo por un partido cohesionado ("Es indispensable transformar la actual organización en un Partido homogéneo, desarrollando la ideología proletaria, poco arraigada aún, introduciendo el marxismo-leninismo en la práctica concreta de los militantes"), ${ }^{20}$ que asumiera la clandestinidad con la disciplina necesaria para actuar como un solo cuerpo ("Las actuales condiciones represivas exigen practicar efectivamente el centralismo democrático"), ${ }^{21}$ y cuya dirección combatiera el faccionalismo ("El combate a muerte a los rezagos de actividad fraccional, es un compromiso que la dirección cumplirá sin vacilaciones"). ${ }^{22}$ En segundo lugar, en una autocrítica y perspectiva que exigía analizar contextualmente las variantes de la táctica y la estrategia, así como la reflexión constante sobre las formas de lucha y alianzas deseables y posibles, todo ello según criterios de análisis de las correlaciones de fuerzas políticas en conexión directa con las posiciones de clase y los efectos que la dictadura estaba materializando en el capitalismo chileno. En tercer lugar, en la idea de que era necesaria la cohesión política de la clase obrera en la perspectiva de construir una "dirección única proletaria", ${ }^{23}$ que fuese la expresión de la "unidad socialista comunista", pues parte de la derrota de la UP se explicaba por la ausencia de una vanguardia proletaria cohesionada. Este último aspecto, si bien estaba lejos de establecer un plan de fusión orgánica entre el PS y el PC, y partía por valorar las tradiciones históricas de ambos partidos, fue interpretado por los sectores socialistas críticos del Documento de Marzo como una tesis "liquidacionista" del socialismo en Chile, que valoraba al PC como partido eje de una dirección proletaria y daba al PS un rol más bien complementario de acercamiento a la pequeña burguesía, todo lo cual redundaría en la subordinación de los socialistas respecto a los comunistas. En palabras de uno de sus críticos, Adonis Sepúlveda: "Es un documento que encierra una filosofía negativa con respecto al Partido (...) cuando a juicio de los autores el Partido se equivocó, se le particulariza, y cuando el PC no estuvo bien se habla de que el núcleo proletario no estuvo bien (...) Nos negamos rotundamente a considerar las Perspectivas del Partido Socialista como las de un instrumento accesorio de la Dirección Proletaria."24

Si bien los lineamientos del Documento de Marzo llegaron a ser hegemónicos en la militancia clandestina interior, durante todo el periodo post golpe y en la segunda mitad de los años setenta surgieron direcciones paralelas y opuestas a sus orientaciones: la ya citada CNR que se distinguía por cierta presencia trotskista ${ }^{25}$ y una evaluación de la derrota como

\footnotetext{
${ }^{20}$ Dirección PS interior, ibid.

${ }^{21}$ Dirección PS interior, ibid.

${ }^{22}$ Dirección PS interior, ibid.

${ }^{23}$ Dirección PS interior, ibid.

24 "Notas sobre el documento del CC, marzo de 1974", documento fechado en abril de 1974 y firmado por "Juan Cristóbal", seudónimo de Adonis Sepúlveda. En compilado de documentos: "Problemas del Partido Socialista de Chile posteriores al golpe militar (1974 - 1981)", México DF, 1984.

${ }^{25}$ El trotskismo era un elemento constante de la vida faccional del PS. Durante los años sesenta, grupos trostskistas habían derivado al MIR, pero varios de esos cuadros retornaron al PS luego de rupturas al interior de la organización liderada por Miguel Enríquez. Sobre esto último: Eugenia Palieraki, “'La revolución ya viene! El MIR chileno en los años sesenta”, Santiago, LOM, 2014.
} 
costo de las políticas "reformistas" promovidas por el $\mathrm{PC}^{26}$; la llamada "Dirección de Consenso" que agrupaba a los ex Militantes Rojos; el Movimiento Revolucionario Manuel Rodríguez (MR2) también llamado "La Chispa" que era una corriente guevarista de socialistas ex miristas ${ }^{27}$; por nombrar algunas de las facciones más importantes. ${ }^{28}$ Como ya se mencionó, varias de estas corrientes que vieron en el Documento de Marzo contenidos liquidacionistas del socialismo chileno, fueron combatidas por la dirección interior, pero recibieron un trato que transitaba entre la ambigüedad y el reconocimiento por parte de la dirigencia de la dirección exterior, lo que generó fuertes críticas tanto desde la dirección interior como desde sus simpatizantes políticos en el exilio. Entre los últimos se contaba la Secretaría Exterior de la JS (dirigida, entre otros, por Camilo Escalona), ${ }^{29}$ que en 1977 sostuvo: "Lesiona profundamente al Partido en el exterior y a la relación franca con la Dirección Interior, el hecho de que aún hoy se permita operar con impunidad a la denominada Coordinadora, que ha adquirido las características de una organización grupuscular ajena y distinta al partido." 30 En definitiva, el periodo post golpe de los años setenta fue un contexto de orgánicas y legitimidades en tensión. Altamirano y su equipo cercano basaban su mando en haber sido elegidos en las instancias democráticas del partido previamente al golpe de Estado, y si bien las direcciones del interior no podían exhibir la misma legitimidad de origen (sus dirigentes pasaron a ser designados verticalmente, lo que en lenguaje partidista se denominó “cooptación”), las condiciones de extrema represión evidenciaban que los dirigentes arriesgaban sus propias vidas, lo que producía un valor y autoridad que no podía ser desconocido. Lo anterior, sin duda, incidió en dilatar el quiebre definitivo del PS y marcó la ambigüedad constante de la dirección de Altamirano.

La suma de estas tensiones significó que a fines de la década del 70 el PS en el exilio apareciera notoriamente dividido en dos bloques. Por un lado, el liderado por Carlos Altamirano con sectores que arrastraban posturas de oposición a los grupos que controlaban el interior y que se oponían a la política derivada del Documento de Marzo. Por otro, el liderado por Clodomiro Almeyda, que proponía una alianza estratégica con el PC y formas leninistas de organización partidista, es decir, contenidos doctrinarios y políticos coincidentes con la dirección interior heredera del Documento de Marzo.

Como modo de resolver el conflicto en torno a la legitimidad de las direcciones, la dirección interior apostó por convocar a un pleno del Comité Central en donde se traspasará definitivamente la dirección desde el Comité Central electo en La Serena hacia la dirección clandestina en Chile. Tal pleno, que fue denominado "de Argel" (pero en realidad fue realizado en Alemania Oriental en febrero de 1978), concluyó con dicha resolución, aunque

\footnotetext{
${ }^{26}$ Ricardo Yocelevzky, "El partido socialista de Chile bajo la dictadura militar”, Foro internacional, volumen 27, número 1, El Colegio de México, Ciudad de México, 1986.

${ }^{27}$ Este grupo se desprendió del MIR en 1969 y se incorporó al PS como tendencia de izquierda revolucionaria. Palieraki, op. cit.

${ }^{28}$ Mauricio Rojas, "La evolución del Partido Socialista de Chile durante la primera parte de la dictadura (1973 - 1979)". Divergencia, número 5, Taller de Historia Política, Santiago, 2014, 9 - 34.

${ }^{29} \mathrm{Al}$ momento del golpe, Escalona era un importante dirigente de la JS, en 1972 destacó por disputar la conducción de la Federación de Estudiantes Secundarios FESES, en elecciones que la UP perdió frente al candidato de la Democracia Cristiana.

30 "Partido Socialista de Chile; Resolución política de la Secretaría exterior de la Juventud Socialista de Chile", Sofía, junio de 1977. Citada en Ortiz, op cit, 243.
} 
manteniendo la secretaría general en Altamirano, ${ }^{31}$ quien evidentemente perdía el control real del partido a manos de los cuadros alineados con el interior. Lejos de adaptarse a su nueva condición, Altamirano resintió la pérdida de poder de su círculo y de sí mismo ("me dejan como reina de Inglaterra" habría dicho, señalando que su cargo pasaba a ser decorativo) ${ }^{32}$ y protagonizó una creciente conflictividad que a ojos de la dirección interior significaba desconocer los acuerdos de Argel y la propia legitimidad de la ahora dirección única del PS. De hecho, entre las acusaciones más graves contra Altamirano estaba que derivaba financiamiento de la solidaridad internacional a fracciones como la CNR. De acuerdo a Germán Correa, lo de Altamirano fue una rebelión abierta en la que usó su cargo de Secretario General para intentar desconocer resoluciones legítimas del partido:

El tipo se había levantado contra todo el partido y además había gastado fondos de la solidaridad para levantar a la militancia en contra de la dirección interior, era una sublevación, era más que fraccionalismo, era una sublevación (...) Desde luego que la dirección interior no iba a aceptar el ultimátum que nos daba de entregarle el poder a él prácticamente. Él estaba rompiendo todas las resoluciones de Argel. (Altamirano) me dice: el partido, ustedes, tienen que tener lo siguiente claro, conmigo todo, sin mi muy difícilmente sobrevivir, y contra mi imposible; esa fue su frase de oro, y esa frase yo la transcribí tal cual, esa era la posición de Altamirano, quería la rendición incondicional de la Dirección Interior. (Germán Correa)

En este clima, durante el Tercer Pleno Nacional Clandestino del PS realizado en 1979 (con reunión final en Berlín) se resolvió la remoción como Secretario General de Carlos Altamirano, su reemplazo por Clodomiro Almeyda y su expulsión del partido. Antes de la reunión final, Altamirano ya se había declarado en rebeldía y desconocía las resoluciones del evento. En el documento del Pleno fechado en abril de $1979^{33}$, se acusaba al expulsado dirigente de tener posiciones personalistas que dañaban la unidad del partido, de la izquierda y de la oposición a la dictadura; de alentar faccionalismos que desconocían la dirección interior ("dar apoyo político y material a la Coordinadora de Regionales"), ${ }^{34}$ y en definitiva, de entorpecer las recientes resoluciones partidarias orientadas a fortalecer una dirección única. Altamirano asumió entonces el quiebre e hizo su propio llamado a un XXIV Congreso del PS (pues el mismo llamado hacía la dirección de Clodomiro Almeyda). Nació ahí el "PS Altamirano" que concitó un apoyo significativo en el exterior. Dentro de

\footnotetext{
31 De acuerdo al testimonio de Germán Correa, los cuadros del interior no deseaban mantener a Altamirano como Secretario General y preferían que asumiera Clodomiro Almeyda, pero este último consideró que era mejor dejar a Altamirano: "Se equivocó Almeyda. Cuando nosotros le dijimos que él tenía que asumir la sucesión de ese pleno, en ese cambio, dice - yo creo que mejor dejar a Carlos porque así lo mantenemos amarrado - Y nosotros decimos no, nosotros queremos que usted sea Secretario General, Altamirano nos ha dado la guerra durante todos estos años, no lo queremos ahí, lo queremos a usted, y Cloro se equivoca y dice no. Él me reconoció tiempo después que había sido un gran error de su parte." (Germán Correa).

${ }^{32}$ En entrevista a Germán Correa.

${ }^{33}$ Resoluciones del Pleno del Comité Central, abril de 1979. Partido Socialista de Chile, Secretariado Exterior, Comité Central.

34 “Resoluciones del Pleno del Comité Central, abril de 1979...” Op cit, 86.
} 
Chile, prácticamente la totalidad de la militancia se consideró parte del que se denominó coloquialmente "PS Almeyda".

\section{"Patrulla juvenil", "pantalones cortos" y "cooptados". Los jóvenes del interior, la lucha por la legitimidad y la otredad altamiranista}

Un elemento importante para entender la dirección interior del PS es un fenómeno de características generacionales: tras el golpe de Estado, la Juventud del partido se disolvió como estructura y sus cuadros se unieron orgánicamente a los adultos, lo que permitió que tanto la primera dirección del PS clandestino como las siguientes estuvieran compuestas mayoritariamente por jóvenes. En la primera dirección, Lorca tenía 29 años, Ricardo Lagos Salinas 22, Víctor Zerega 26, siendo uno de los mayores Exequiel Ponce que tenía 37 años en 1973. En las estructuras que sucedieron a la primera dirección clandestina (que se fueron articulando con dificultad, y con cambios en su composición, pues varios de sus nombres fueron víctimas de la represión), la presencia de cuadros veintañeros se mantuvo, lo que motivó que recibieran nombres que destacaban justamente su condición juvenil (o su poca experiencia), como "patrulla juvenil", "los tiernos" y los "pantalones cortos". ${ }^{35}$ Hacia 1976 se consolida una dirección clandestina integrada en gran medida por estudiantes y jóvenes que rondaban los 20 años (como el caso de Ricardo Solari de 22 y Eduardo Gutiérrez de 25), más algunos dirigentes algo mayores que venían trabajando clandestinamente (como Germán Correa de 36). A medida que esta dirección se fue consolidando, se sumaron otros experimentados dirigentes adultos afines a las perspectivas predominantes en la dirección, como Albino Barra, Akín Soto, Augusto Jiménez y Julio Stuardo. Sin ninguna posibilidad de instalar cuadros dirigentes por vía democrática, ocurrió que la dirección nombraba los militantes clandestinos que asumían las riesgosas labores de dirección. Como ya se mencionó, estos cuadros dirigentes designados por la jerarquía clandestina se denominaron "cooptados", y fueron los que dirigieron el partido que en la década de 1980 se conoció como "PS Almeyda".

Yo entré a la Dirección Nacional después de la caída de la Dirección en junio de 1975, cuando ya la represión se hizo más intensa sobre el PS. Y éramos bien jóvenes, yo me debo haber incorporado a la Dirección Nacional, a los 21 años, en el año 76 (...) El escenario era mucho más crítico que la pura represión (...) La división del exilio socialista fue muy grande y fue muy dura; después se acentuó cuando nosotros con la alianza de Clodomiro Almeyda y con otros dirigentes del exterior, provocamos el quiebre con Altamirano (...) Y ahí nosotros empezamos un proceso bien interesante de recuperación de viejos cuadros socialistas, que habían sido oposición a Altamirano (...) Fuimos creando una dirección política muy compuesta, en donde nosotros ya no éramos solo el núcleo de la JS, sino que pudimos incorporar a un grupo de dirigentes de mucha más experiencia y visión política. (Ricardo Solari)

Está la primera (dirección) que es la de Ponce que cae el 75, viene la que después le llamó Altamirano peyorativamente la Patrulla Juvenil (...) Una

\footnotetext{
${ }^{35}$ Denominaciones que tanto en la bibliografía como en testimonios se suelen adjudicar a Altamirano.
} 
segunda dirección donde está Gregorio Navarrete, el Negro (Eduardo) Reyes, Ivan Parvex, hay un lote de gente ahí que hoy día son gente que tiene entre 60-65. Cuando caen ellos (capturados por la DINA), caen entre diciembre y enero de 1976, a ellos los reemplazan los de "pantalones cortos", "los tiernos" como nos decían. (...) Y entro yo con ellos. Yo venía trabajando con la dirección clandestina desde octubre del 73(...) Yo fui de los cooptados, claro, porque este era un grupo de cabros, cabros muy cabros, 17, 18, 20 años, cabritos, si eran de la Juventud Socialista y que no eran conocidos, entonces ellos reclutan gente más vieja, como yo, que en esa época yo tenía 33 años, 35, 36. Cooptan a Albino Barra que en esa época tenía unos 60 y había sido diputado del PS por muchos años, Akin Soto que había sido dirigente obrero de los puertos en San Antonio, reclutan al viejo Jara, Augusto Jiménez Jara, que había sido subsecretario del Trabajo de Allende, Stuardo. Los cabros tuvieron la sabiduría y necesidad de reclutar gente que tenía un poco de trayectoria, porque nadie los conocía a ellos, entonces estaba el problema de la legitimidad. Pero quienes conducían el partido eran ellos. (...) A mí me reclutan para la instancia que dirigía el partido, había dos instancias en ese momento, una que se llamaba el Comité Ejecutivo, donde estaba Eduardo Gutiérrez, Silvio Espinoza, Ricardo Solari, el hijo de Albino Barra, y yo, éramos cinco. E idearon una Comisión Política donde pusieron a unos viejos. Como los viejos eran muy conocidos, y no los podían tener dirigiendo clandestinamente al partido, quienes dirigen y organizan el partido son el Comité Ejecutivo. (En la) Comisión Política estaba Albino Barra, Augusto Jiménez, Akín Soto, y Eduardo Gutiérrez. Eduardo, en cuanto coordinador del Comité Ejecutivo iba a las reuniones de la Comisión Política. (...) Nosotros cambiamos eso como el 78, terminamos con el Comité Ejecutivo y pasamos a ser Comisión Política. (Germán Correa).

Hubo un pleno al que se le llamó "Pleno de las Amapolas", que fue una reunión de gente joven, entre las cuales estaba yo. Ahí se formó una (segunda) dirección, yo no estaba en esa dirección, y esa dirección cayó en diciembre (1975). Caen (capturados por la DINA) (Iván) Parvex, (Gregorio) Navarrete, Oscar de la Fuente, Juan Carvajal ${ }^{36}$ (...) En enero (1976) hay una reunión donde estábamos cinco compañeros, Ricardo García, Jaime Lorca. Decidimos afrontar lo que se nos venía encima. Éramos tipos jóvenes, 23, 24, 25 años, yo parece que era el mayor (...) Decidimos comenzar un proceso de cooptación, o sea de incorporar gente a la dirección del partido. La cooptación era la "dedocracia". O sea, tú entregabas el antecedente, uno de los cinco decía: mira, yo conozco a tal persona. Lo vinculábamos, le conversábamos, entonces así logramos reconstruir un grupo más o menos de treinta personas. (...) Había una suerte de Comité Central, se autoproclamó una Comisión Política que comenzó a funcionar, que tenía el control de este aparataje pequeño. Y empezó la lucha por la legitimidad. (Eduardo Gutiérrez)

A principios de 1980, rotos ya los vínculos con el sector dirigido por Altamirano, el ahora PS Almeyda era el que concentraba la gran mayoría de la militancia interior y

\footnotetext{
${ }^{36}$ Los cuatro militantes mencionados sobrevivieron a su paso por los centros de detención y tortura.
} 
contaba con bases en los frentes sociales (laboral, territorial y el estudiantil), mientras que el PS Altamirano concentraba su mayor presencia en el exilio socialista. En ese momento, para el "almeydismo" la distinción con los "altamiranistas" no se fundamentaba en cuestiones que luego serán relevantes, como los revisionismos en torno al marxismo leninismo (característicos de la "renovación socialista"), o la discusión política en relación a las alianzas y las formas de lucha contra la dictadura. De hecho, durante aquel inicio de década, una idea común en la militancia lorquista en Chile seguía siendo que Altamirano y los suyos representaban la irresponsabilidad y el caudillismo de un "izquierdismo vociferante", faccionalista (de "montonera"), indisciplinado, que primero había dañado al gobierno de Allende y luego cuestionado la legitimidad de la dirección interior durante la dictadura.

La decisión nuestra de provocar la ruptura, en el fondo, tenía dos grandes afluentes, una, la crítica muy dura que nosotros teníamos a la conducción socialista del periodo 70-73. Y, segundo, ya se empezaba a esbozar una suerte de discusión respecto de proyectos. (Ricardo Solari)

Se apelaba a las características del Partido Socialista durante la UP, que fue un Partido montonera, que fue un Partido que no tuvo disciplina, que no tuvo orden. (Jaime Pérez de Arce)

Altamirano de alguna manera representaba para nosotros, para mí en particular, representaba una posición frente al gobierno de la UP, que a mí no me gustó (...) Una de las discusiones era el apoyo a la dirección del PS en el interior, que era donde estaba Exequiel Ponce y Carlos Lorca, toda esa gente que habían sido detenidos, pero que era la lógica de la continuación del PS. Ahora, toda esa gente que era la continuación del PS, no era gente de Altamirano, ¿me entiendes? era gente que fue siempre allendista. (Paulina Veloso)

Altamirano había elaborado un libro que se llamaba algo de la derrota, ${ }^{37}$ que era la continuidad del discurso histórico de Altamirano digamos; la lucha de clases, bla bla bla... Nosotros nos quedamos con ese Altamirano. A nosotros lo que nos molestaba en esa época era este intento de no respetar la dirección interior, ese era el tema político. (Eduardo Gutiérrez) Lo que se oponía a Altamirano era Carlos Lorca, o por lo menos así se transmitió la historia a nosotros, en el sentido de esa frivolidad revolucionaria, de esa verborrea, esa retórica, porque nosotros éramos muy contrarios a todo eso, o nos formamos muy contrarios a todo eso, y, por lo tanto, entrar al PS Almeyda para mí estaba bien. Fue muy curioso, porque en el fondo uno, cuando se fue Altamirano, o lo echaron, o se dividió, era como que se iba el grupo más ultraizquierdista, pero al final era una escisión que era más bien a la derecha, al revés (...) Nosotros la vivimos como en realidad sacar a un ultra izquierdismo irresponsable,

\footnotetext{
${ }^{37}$ Se refiere al libro "Dialéctica de la derrota" editado en 1977. Allí, el diagnóstico de Altamirano pone énfasis en el error de sobrevalorar las posibilidades de una vía pacífica al socialismo y no considerar la inminencia de una ruptura violenta en que se definiera el dominio de clase por vía armada. Efectivamente, el tipo de análisis no incorpora elementos centrales del pensamiento de la renovación que aparecerán con posterioridad, como el rechazo a la vía armada revolucionaria y la apuesta por un socialismo dotado del pluralismo político propio de la democracia liberal. Ver: Carlos Altamirano, Dialéctica de la derrota, México, Siglo XX1, 1977.
} 
retórico, frívolo, y que además no se quedaron en Chile, mientras los otros habían sido masacrados. (Ernesto Águila)

Tuvo que pasar un buen tiempo hasta que en 1983 estos "otros socialistas" fueron vistos y nombrados por el almeydismo como "renovados", "cercanos al centro político" y adversarios de un "nosotros" situado a su izquierda. Para entonces, la izquierda de Europa occidental había influido en el círculo cercano a Altamirano, contextualizando un proceso reflexivo que al tiempo que acentuó una distancia con los socialismos de Europa del Este, incorporó revisionismos del marxismo que orientaron un objetivo fundamental: articular una "concepción coherente entre las relaciones entre socialismo y democracia". ${ }^{38}$ La idea de la democracia representativa como fin unido al socialismo caracterizó esta sensibilidad que se fue perfilando como orientación contraria a la ortodoxia soviética, a las concepciones estratégicas y valoraciones orgánicas leninistas, y a la concepción de una alianza fuerte con los comunistas como pilar ineludible de toda política de alianzas. Sin embargo, la "renovación" cubría un espectro más estrecho que la totalidad de grupos que durante la división fueron altamiranistas por oposición a la dirección interior. Esto trajo nuevas divisiones que terminaron por definir dicho Partido Socialista como fracción autónoma completamente involucrada con las orientaciones de la renovación socialista. ${ }^{39}$ Por su parte, el sector almeydista, si bien nacía desde la valoración de la cohesión interna, tempranamente fue dando lugar a emergencias faccionales.

Poco antes del quiebre, en 1978, el PS interior dio inicio a un esfuerzo por reconstruir la Juventud como orgánica. Para ese objetivo se nombró una Comisión Nacional Juvenil CNJ, que operó como dirección directamente dependiente de la Comisión Política del partido, y teniendo como rol reconstruir la Juventud Socialista. A partir de entonces, la socialización de las nuevas generaciones militantes se produjo en estructuras

\footnotetext{
${ }^{38}$ Cita del Informe de Carlos Altamirano al Pleno Socialista conocido como "de Argel" en 1978 (nombre destinado a engañar a los servicios de la inteligencia chilena, pues en realidad se realizó en Alemania Oriental). Según Jorge Arrate, allí el Secretario General del PS en el exterior comenzaría a esbozar ideas de lo que luego se conocerá como "renovación socialista". En Arrate, op. Cit., 286. En general, la interpretación de los renovados (entre los cuales se cuenta Arrate) tiende a destacar signos tempranos de la renovación en la división de 1979. El propio Altamirano, en sus conversaciones con Gabriel Salazar recuerda el quiebre como un rompimiento con la "ortodoxia marxista-leninista" y la recuperación de una línea doctrinaria "esencial" o tradicional del partido. Sin embargo, Ricardo Núñez reconoce que en el momento del quiebre: "los temas ideológicos están en el trasfondo, pero no están puestos en el primer lugar del debate. Para muchos de los que estaban en Chile, Altamirano seguía siendo visto como la figura 'dura' de los tiempos de la Unidad Popular". Fernández, op cit 197. Ver además: Gabriel Salazar, Conversaciones con Carlos Altamirano. Memorias Críticas, Santiago, Debate, 2010, 406 - 407.

39 En la segunda mitad de los setentas, la imagen de un Altamirano “izquierdista" también circuló entre los que desconocían la dirección interior en Chile; en el exterior, de hecho, grupos radicales y distantes de la vía Chilena al Socialismo, en un principio se unieron a Altamirano asumiendo que con él había una orientación crítica del "reformismo culpable de la derrota". Ese fue el caso del MR2-La Chispa, grupo liderado por Ruiz Moscatelli que durante el quiebre de 1979 se unió al altamiranismo, hasta que las diferencias con la "renovación socialista" no tardaron en aparecer, fundamentalmente en aspectos estratégicos, como el que La Chispa fuese partidaria de desarrollar una resistencia armada para enfrentar la dictadura. En esas circunstancias, el antiguo MR- 2 quebró con el PS altamiranista (o PS XXIV Congreso) que para entonces lideraba Ricardo Núñez, formando una nueva fracción que llamó PS XXIV Congreso-La Chispa. La reivindicación para sí del XXIV Congreso (que convocó Altamirano y se realizó en 1980) se debía, entre otras cosas, a que sus posiciones fueron mayoritarias en las reuniones congresales en Chile, expresándose también dicha mayoría en los delegados enviados a la reunión final en París. Quien fue elegido Secretario General del PS durante aquel XXIV Congreso, Ricardo Núñez, recuerda: “... si bien yo fui electo delegado, la mayoría de los delegados de Chile salieron de La Chispa. Por ende, las posiciones que llevamos desde Chile, aun cuando uno no las compartiera, habían sido impuestas por este sector”. En: Fernández, Op cit 209.
} 
específicamente juveniles en los ámbitos estudiantiles y poblacionales. Materializado el quiebre de 1979, la orgánica juvenil pasó íntegramente al PS Almeyda. En el verano de 1985 se organizó una conferencia clandestina, la XXI Conferencia Nacional, desde la que emergió un Comité Central de la Juventud, es decir, se disolvió la CNJ y la JS retornó como estructura socialista con dirección autónoma respecto al partido. Al año siguiente, la JS convocó a una conferencia de prensa para hacer público a quien asumía como Secretario General de la organización: Jaime Pérez de Arce. Mucho menos avanzados en su orgánica, los jóvenes de la renovación iniciaron recién en 1983 un lento proceso de articulación, hasta que en la segunda mitad de los años 80 pudieron tener un referente más pequeño que la JS y cuyo nombre, "Federación Juvenil Socialista - FJS", decía mucho respecto de los deslindes identitarios que establecían frente a los jóvenes almeydistas y su herencia lorquista. $^{40}$

\section{"Lucha de masas rupturista con perspectiva insurreccional". Identidad almeydista y quiebres internos en los años 80}

Si bien hasta 1979 no se percibieron tensiones divisorias en la estructura del PS interior, la década del ochenta fue para los ahora almeydistas una dura prueba en el intento de mantener la cohesión del partido. Por un lado, estuvo la intensa discusión en torno a las formas de lucha, las políticas de alianzas y las condiciones de una eventual unidad socialista, todo ello en un contexto crítico para la dictadura, entre la crisis económica y las protestas nacionales en 1982 y 1983. Por otro lado, las dificultades propias de la clandestinidad y la diáspora, como el hecho de que el propio Secretario General, desde el exilio, no accediera de primera fuente a las discusiones, posiciones y lógicas de la interna partidista en Chile.

Un punto de inicio de esta coyuntura crítica fue una serie de reuniones que la prensa informó como esfuerzos concretos de las "principales corrientes socialistas" por producir una reunificación del socialismo chileno. En este marco, en septiembre de 1981 nació el llamado "Comité de Enlace Permanente" con la intención de desarrollar conversaciones y coordinaciones entre los diferentes grupos del fragmentado PS. En abril de 1983 los miembros del comité anunciaron que la instancia evolucionaba a "Comité Político de Unidad" CPU, erigiéndose como "representación política del PSCH en el periodo de reunificación partidaria" con "atribuciones resolutivas necesarias para adoptar las medidas tendientes a la concreción de los objetivos de la unidad". ${ }^{41}$ Las revistas de oposición Análisis y Apsi informaron que los firmantes de estos acuerdos incluían al almeydismo y a la corriente que en 1979 siguió a Altamirano, más otros grupos como "los suizos", la "USOPO"42 y los "humanistas", destacando también la ausencia de grupos como la CNR y

\footnotetext{
${ }^{40}$ Ver nota al pie número 13.

${ }^{41}$ En: Acuerdos y conclusiones para la unidad del Partido Socialista de Chile. 19 de abril de 1983. Aparecen como firmantes del documento: Partido Socialista de Chile (XXIV Congreso), Partido Socialista de Chile (Consenso), Partido Socialista de Chile (Sec. Gral. Almeyda), Partido Socialista de Chile (MAS - USOPO), Partido Socialista de Chile (Tendencia Humanismo Socialista), Partido Socialista de Chile (Suizos).

${ }^{42}$ La Unión Socialista Popular, USOPO, fue una facción socialista autónoma que fundó Raúl Ampuero en 1967. Se disolvió después del golpe de Estado y se reconstruyó en la década de 1980 con la dirección de Ramón Silva Ulloa.
} 
La Chispa. ${ }^{43}$ Sin embargo, la propia prensa constató que en el almeydismo no había consenso y se presentaría cierta disconformidad con los acuerdos por parte de un sector denominado "los comandantes", que según revista Análisis, representaría "el fuerte del partido socialista de Chile (de Almeyda)". ${ }^{44}$ De acuerdo a los testimonios recogidos, los principales miembros del almeydismo que acudieron a esos encuentros: Akín Soto y Julio Stuardo, eran parte de una corriente interna que se denominó coloquialmente "guatones" (modo de decir "conservador", "tradicional" o "moderado"), ${ }^{45}$ y que tenía entre sus propósitos justamente la priorización por la unidad socialista y asumir las consecuencias que ello tuviera en las políticas de alianza con el espectro opositor. Esto último no era un punto menor, considerando que el PS liderado primero por Altamirano y luego por Ricardo Núñez daba señales de acercarse al centro político y manifestar distancia con los comunistas (aunque en ese momento el lema seguía siendo "gran alianza opositora con todos los sectores democráticos"). ${ }^{46}$ De hecho, en marzo de 1983, las implicancias políticas de estos planes unitarios fueron quedando más claras cuando la mencionada corriente de "los guatones" apareció firmando, a través de Stuardo, el Manifiesto Democrático, aquél pronunciamiento de líderes políticos que involucraba desde grupos de la derecha liberal, hasta estos líderes del PS Almeyda, pasando por el PS dirigido por Núñez y la Democracia Cristiana. En agosto de 1983 los mismos Stuardo y Soto aparecieron como miembros de la Alianza Democrática, junto a las corrientes socialistas renovadas unidas en el CPU, la Democracia Cristiana, el Partido Liberal y el Partido Radical, e hicieron declaraciones en que manifestaron críticas a la "tesis de la rebelión popular", gesto que sin duda condicionaba o cuestionaba la alianza del PS con los comunistas. ${ }^{47}$

La coyuntura entre abril y septiembre de 1983, fue particularmente difícil para el almeydismo. Primero, porque este partido no estaba plenamente involucrado en las iniciativas por la unidad, no había un consenso sobre los logros que ellas exhibían, y los militantes que asistían a las reuniones del CPU no tenían el carácter de representantes de la Comisión Política del partido. ${ }^{48}$ En segundo lugar, porque al interior del PS ya había una conciencia respecto a la existencia de corrientes internas, y se asumía que aquellos que se habían involucrado con el proceso de unidad eran de una tendencia determinada, que a los

\footnotetext{
${ }^{43}$ En general, la prensa opositora presentó estas resoluciones como concreción de la unidad socialista. Revista Análisis, por ejemplo, se refirió al Comité Permanente de Unidad como la Comisión Política de la "nueva colectividad", es decir, de un PS unificado. Ver: Irene Geis, "La política al rojo vivo", Análisis, número 57, mayo de 1983. De hecho, hasta septiembre de 1983 tanto Apsi como Análisis seguían dando a entender que la unificación del PS había sido un hecho. Ver: "Unidad socialista, una experiencia necesaria”, Análisis, 13 a 27 de septiembre de 1983; María Ester Aliaga, “En qué está la izquierda?", APSI, 20 de septiembre al 3 de octubre de 1983.

${ }^{44}$ En: Irene Geis, "La política al rojo vivo"...

45 En la historia del PS el término "guatón" se había ocupado, más que para referirse a una facción en particular, para señalar aquellas posiciones más moderadas o socialdemócratas. En diversos contextos se usó en relación a liderazgos como los de Aniceto Rodríguez o el propio Allende.

${ }^{46}$ En: Felipe Pozo, “¿La oposición a la cancha?”, Análisis, marzo 1983.

${ }^{47}$ Los comunistas sostenían la Política de Rebelión Popular de Masas, que legitimaba todas las formas de lucha contra la dictadura, incluida la violencia armada. Las citadas declaraciones son de septiembre de 1983, cuando Soto y Stuardo ya habían adherido a la Alianza Democrática y continuaban considerándose parte del PS Almeyda. Ver: "Unidad socialista: una experiencia necesaria", Análisis, 13 al 27 de septiembre de 1983.

48 Dice Germán Correa: "El Comité de Unidad, para nosotros, era: 'vayan si quieren'. Yo participaba en la Convergencia Socialista sin mandato de la Comisión Política (...) Estábamos, pero no estábamos representando al partido, como tampoco estaban ni Akin, ni Stuardo representando a la Comisión Política. Eran frentes que, nosotros decíamos, no podemos ignorar, pero que tampoco vamos a estimular, hay que estar ahí para escuchar, ver qué pasa, en fin, estar atentos, pero no era nuestra preocupación central".
} 
ojos del resto, estaba tomando decisiones que sobrepasaban las posiciones del partido y su dirección.

Es este momento en donde se habla de dos tendencias nítidas. Por un lado, la que representaban Stuardo y Soto, que se acercaba al PS que lideraba Ricardo Núñez y al espectro de la renovación contenido en la Convergencia Socialista. ${ }^{49}$ Como se dijo, esta corriente compartía con el socialismo de la renovación la idea de construir una alianza con el centro y una derecha democrática, y en tal sentido, dieron señales tan contundentes como firmar el Manifiesto Democrático, unirse a la Alianza Democrática y hacer público un distanciamiento con el PC. Por otro lado, los que serían los más duros oponentes a dicha facción, los llamados "comandantes", que apostaban por afianzar la alianza con los partidos que planteaban la legitimidad de todas las formas de lucha contra la dictadura (PC y el MIR) y deseaban que el PS avanzara en la puesta en práctica de una perspectiva insurreccional para derrocar a Pinochet. En ese momento se comenzó a utilizar otro término, que tiempo después adquirió otro significado y tomó forma de facción: "los terceristas". Según cuenta Germán Correa, el nombre surgió casi casualmente como necesidad de mencionar a los no alineados con "comandantes" ni con "guatones", y que de acuerdo a la percepción de Correa habría sido el grupo mayoritario:

Paso a Berlín, a reunirme con el Cloro (Clodomiro Almeyda), y eso debió haber sido marzo-abril del 83. Poco antes había estado Akin Soto, entonces me encuentro con Almeyda súper preocupado (...) Akin Soto le había contado un cuadro de que el partido estaba a punto de dividirse en Chile. Y yo le digo a Almeyda que nada que ver, que sí existe en Chile una fuerte pugna entre un lote chico de gente en posiciones más duras, en donde está Eduardo Gutiérrez, y por otra parte, le dije yo, el de los viejos guatones, que usted conoce po Cloro, el Akin, el Julio (Stuardo) (...) En esa reunión yo le digo a Almeyda: pero Don Cloro, el grueso del Partido no está en esa, el grueso del partido, le dije, está más bien en posiciones eh... y no hallaba la palabra, y no quise decir neutral, porque no era neutral, y le digo "el resto Don Cloro está, está en una posición tercerista, no está ni una ni en la otra, el grueso del partido estamos en una perspectiva muy distinta, no estamos muy metidos en esa pugna ideológica absurda entre esos dos lotes que son chicos”. (Germán Correa)

Entre los meses de agosto y septiembre de 1983, mientras el país estaba conmocionado por la irrupción de las protestas nacionales contra la dictadura y se asumían definiciones claves para la organización de la oposición, se produjo una fuerte crisis en el PS Almeyda, la que escaló al punto de que el partido llegó a estar sin una dirección que gozara de plena legitimidad. Esta coyuntura es poco conocida porque no apareció en la prensa de la época y tampoco se detalla (con su carácter de crisis) en los documentos del

\footnotetext{
${ }^{49}$ Se denominó Convergencia Socialista a un proceso de reuniones y acercamientos que desde el año 1980 venían desarrollando algunas fracciones del PS más la Izquierda Cristiana y los dos MAPU. Esta organización llegó a formalizar un secretariado con representantes de los partidos en el interior del país durante 1982, para luego dar lugar al Bloque Socialista en 1983. Aunque el almeydismo participó de las conversaciones de la Convergencia, hacia 1983 no concurrió a la formación del Bloque Socialista, referente que fue su resultado directo.
} 
PS. Por lo mismo, la reconstrucción que se expone a continuación es realizada fundamentalmente a partir de testimonios.

Hacia agosto de 1983, mientras Soto y Stuardo estaban participando de las reuniones del CPU y de los esfuerzos por materializar la Alianza Democrática, el Secretario General del PS, Clodomiro Almeyda, tomó la decisión de zanjar las disputas internas desde un golpe de autoridad que, de acuerdo al testimonio y la perspectiva de Germán Correa, se ponía del lado del diagnóstico y la apuesta que sostenían los líderes del llamado sector "guatón" del almeydismo. En aquel momento, el máximo líder socialista convocó a una reunión en Buenos Aires con representantes del Secretariado Exterior y la Comisión Política que había sido recientemente elegida en Chile en un pleno del Comité Central. En Buenos Aires, Almeyda forzó el nombramiento de una nueva Comisión Política en donde se incluyó a su hermano Manuel Almeyda como Subsecretario General y se tomaron decisiones como ir a la unidad socialista con todas las definiciones políticas que ello implicaba, es decir, se votó sumarse a los esfuerzos de convergencia con el centro político que realizaba el CPU (que en ese mismo mes de agosto materializaron la Alianza Democrática). ${ }^{50}$ Todas estas resoluciones fueron desconocidas en Chile por los "comandantes" liderados por Eduardo Gutiérrez ${ }^{51}$ y por los que hace poco Correa había definido como "terceristas", es decir, por prácticamente la unanimidad de la militancia interior (si consideramos que "los guatones" eran más bien un puñado de dirigentes y no una sensibilidad faccional extendida). Al no acatar el golpe de fuerza que dio Clodomiro Almeyda, la militancia interior rechazó también la unidad socialista en las condiciones en que se estaba dando, decidió no ingresar a la ya naciente Alianza Democrática, y optó por levantar un referente de izquierda que terminó agrupando al PS Almeyda, al PC y al MIR: el Movimiento Democrático Popular MDP, fundado el 20 de septiembre de $1983 .{ }^{52}$ Poco antes, con fecha seis de septiembre, el socialismo de la renovación y los partidos de la llamada Convergencia Socialista fundaron el Bloque Socialista. ${ }^{53}$

Finalmente, el propio Manuel Almeyda se sumó a la "rebelión" contra su hermano, y Clodomiro tuvo que ceder a la línea política que impusieron los "terceristas" y los "comandantes". Esto marcó el quiebre definitivo con Soto y Stuardo. Con anterioridad, el 4 de septiembre, estos dirigentes habían anunciado, junto a la dirigencia del CPU, la unidad socialista, es decir, que el CPU derivaba en dirección del Partido Socialista Unificado. Sin embargo, dado el devenir de los acontecimientos, la publicitada unidad sólo significó que

\footnotetext{
${ }^{50}$ De acuerdo al testimonio de Germán Correa, quien califica en duros términos este momento (habla de "encerrona" y "golpe" dado por Almeyda), se contaron los votos de los presentes en la reunión, habiendo sólo tres personas de la Comisión Política elegida en Chile, los que fueron minoría frente al secretariado exterior que respaldó cada uno de los puntos que propuso el Secretario General.

${ }^{51}$ De acuerdo al propio Gutiérrez, el nombre de "comandantes" provino del modo irónico con el que Julio Stuardo se refería a ellos. En Eduardo Gutiérrez, Ciudades en las sombras. Una historia no oficial del Partido Socialista de Chile, Santiago, Editores Asociados, 2010.

${ }^{52}$ En un comienzo los promotores del MDP invitaron también a la Izquierda Cristiana y al MAPU Obrero Campesino, pero dichos conglomerados no se sumaron y conformaron el Bloque Socialista junto a la otra fracción MAPU y diversos grupos de convergencia socialista. De todos modos, tanto testimonios como la prensa señalan la presencia en el MDP de algunas agrupaciones menores del espectro socialista como la CNR, la facción conocida entonces como La Chispa o XXIV Congreso y un sector del MAPU Obrero Campesino que rompió con la conducción de Jaime Gazmuri y que fue conocido como MOC-Aravena en alusión a su Secretario General. De hecho, hacia 1986 la cercanía entre La Chispa, la CNR y el almeydismo al interior del MDP motivó llamados a materializar la unidad de tales sectores. Por ejemplo: "Los Socialistas por la Unidad Socialista”, inserción del PS XXIV Congreso (La Chispa), Análisis, 11 al 17 de febrero 1986.

${ }^{53}$ Ver: Solicitada: Manifiesto de los Socialistas Chilenos. Revista Análisis, 11 al 25 de octubre de 1983.
} 
algunos grupos y facciones ${ }^{54}$ se sumaran al PS dirigido por Núñez. ${ }^{55}$ Para Germán Correa, la situación ejemplificaba que, en realidad, no existió un almeydismo que a modo de partido personalista siguiera a todo evento las directrices de su líder en el exilio. En una lectura coincidente, Jaime Pérez de Arce sostiene que fue el almeydismo el que debió convencer a Almeyda de la necesidad del MDP y no al revés. En esta oportunidad, los socialistas del interior orientaron al líder del exterior, y hasta cierto punto, lo disciplinaron, apelando a la institucionalidad partidaria y a no repetir las lógicas de acción dirigencial que pensaron erradicadas con la expulsión de Altamirano en $1979 .{ }^{56}$ Germán Correa y Jaime Pérez de Arce recuerdan:

Cloro nos notifica que él va a reunir el Comité Central en Buenos Aires, nos cita a la Dirección Interior, al Secretariado Exterior y a la Comisión Política (...) Antes de ir a esa reunión nosotros tuvimos un pleno del Comité Central y como parte del pleno elegimos a la nueva Comisión Política (...) Y es esa Comisión Política la que envía una delegación a la reunión (...) Nosotros no pedimos ni 50\% de los votos, ni nada, fuimos a una reunión, y se votaron cosas, y ¿qué cosas se votaron? Unidad Socialista, ir a marcha forzada a la Unidad Socialista, no quedar fuera. Segundo, eso significaba que en la política de alianza había que ir a la política que hicieran los socialistas unidos, y si era la Alianza Democrática, la Alianza Democrática. Ahí en ese momento se produce una especie de mini-golpe interno por parte de Almeyda, a la Dirección Interior (...) Almeyda impone a su hermano Manuel Almeyda como subsecretario general, nosotros hasta ese momento nunca habíamos tenido una autoridad unipersonal en Chile (...) (Lo pone) para que le de confianza, en el fondo, es un gesto tremendo de desconfianza hacia la Dirección Interior (...) Ahí (en Buenos Aires) se nombra a la nueva Comisión Política y yo informo ahí que ya hay una Comisión Política elegida por el pleno del Comité Central que habíamos realizado en Chile antes de ir para allá, cinco días antes, eso es desconocido por Almeyda y él hace elegir una Comisión Política de su confianza en el fondo, en que el único miembro que se repite en las dos Comisión Política soy yo (...)

\footnotetext{
${ }^{54}$ Por ejemplo, el grupo de intelectuales llamado "Los Suizos", la Unión Socialista Popular USOPO y la corriente conocida como "Humanismo Socialista”. Ver: María Ester Aliaga, “¿En qué está la izquierda?, APSI, 20 de septiembre a 3 de octubre de 1983.

${ }^{55}$ En un documento de octubre de 1983 editado por el Secretariado Exterior, se da la siguiente información sobre los representantes del PS Almeyda en el CPU (o CPUS): "El 4 de septiembre varios miembros del CPUS dieron una conferencia de prensa en la que anunciaron que a partir de ese momento se constituían en dirección del 'Partido Socialista Unificado'. De esta forma hicieron abortar el proceso de unificación real de los socialistas, para lo que contaron con el apoyo de quienes hasta ese entonces representaban al Partido Socialista en dicha instancia unitaria. Esta unificación prematura y cupular obedece tanto a las ansias de figuración de algunas personas con prácticamente ningún respaldo militante -que por tanto temían quedar en posiciones irrelevantes en un proceso de unidad real, desde la base y los frentes de lucha-, como al interés de los sectores más derechistas del CPUS de impedir que todos los socialistas se incorporaran al MDP (impulsado por el Partido Socialista) favoreciendo así los planes exclusionistas de las fuerzas de centro, y a los intereses imperialistas de promover un recambio de Pinochet que abra espacio a una democracia restringida que margine del sistema político a las fuerzas revolucionarias". En: Cuadernos de orientación socialista número 16. octubre de 1983. Editada por el Secretariado Exterior, Berlín. Página 16.

${ }^{56}$ En los documentos del PS la reunión de Buenos Aires de agosto se presenta como "pleno del comité central realizado en un lugar de América Latina", y se señala la existencia de otra reunión del comité central realizada en Chile. Sin embargo, no se detalla el carácter de la crisis que se vivió entre una y otra reunión. ibid.
} 
Silvio Espinoza, el Negro Espinoza, lo increpó directamente a Almeyda, le dijo "usted está llevando al desastre al Partido Socialista, una vez más un Secretario General del partido, como Altamirano, está llevando al Partido Socialista al desastre en medio de una situación súper compleja en Chile" (...) Cuando yo regreso a Chile el Comité Central se reúne y rechaza la resolución de Buenos Aires, Unidad Socialista incluida. Quedamos con una Comisión Política que era reconocida en Chile por el Comité Central de Chile, pero que no es reconocida por Almeyda y el Secretariado Exterior, y una Comisión Política elegida por Almeyda y el Secretariado Exterior, con minoría nuestra en Buenos Aires, que no es aceptada acá. O sea, quedamos sin Comisión Política (...) Entonces durante los meses más cruciales de la política chilena en esos años, que son julio, agosto del 83, hasta septiembre del 83, el Partido Socialista de Almeyda no tiene cabeza, y la única cabeza con las dos legitimidades era yo (...) Nosotros comenzamos a debatir, bueno, que si hay una Alianza Democrática que representa las posiciones de centro-derecha de este país donde hay algunos renovados medio derechistas socialdemocratizados ahí - esa era la visión que teníamos - nosotros tenemos que mantener la política permanente del Partido Socialista de Chile que hemos tenido durante décadas y durante la dictadura, que es la unidad de la izquierda, y eso qué significa, que si se monta un referente, como hablábamos en esa época, centro izquierda o centro-derecha, con una mezcla de derecha también, como Alianza Democrática, nosotros tenemos que levantar un referente democrático popular, y ese fue el consenso (...) Convoqué a una reunión, un grupo como de 11 o 12 personas en que había entre miembros de la Comisión Política y otros compañeros que tenían peso y vocería dentro del PS Almeyda, donde estaba Manuel Almeyda (...) Y yo puse este dilema, de que si nosotros vamos por la posición de levantar un referente democrático popular con el resto de la izquierda, vamos a romper con el Secretario General que acaba de imponernos meternos a la Unidad Socialista que está terminando en una alianza de centro-derecha, la Alianza Democrática, y que de nuestro punto de vista traiciona la línea política que venimos siguiendo (...) Y todos esperando ver lo que decía Manuel Almeyda, pero Manuel que siempre fue un izquierdista, cuando interviene dice "bueno, yo estoy de acuerdo con la propuesta que está diciendo Germán, estoy de acuerdo que tenemos que levantar un referente democrático popular, y si a Cloro no le gusta, que no le guste, y si nos quedamos sin el Cloro, nos quedamos sin el Cloro". Nos aliviamos al tiro. Y (Eduardo) Loyola dijo: ya, seguimos siendo Partido Socialista Almeyda entonces, con otro Almeyda. (...) Pero (Clodomiro) Almeyda, que de leso no tenía nada, cuando se le comunica telefónicamente a los compañeros en Francia, para que se comuniquen a Berlín, que el partido ha tomado esta resolución, Almeyda se matriculó, no se demoró ni dos horas en matricularse (...) Por eso yo creo que el almeydismo adscrito a Almeyda no existió, nosotros éramos un partido, éramos serios, increpábamos a los dirigentes, nosotros éramos súper autónomos, nosotros además ejercíamos nuestro poder y nuestra dirección acá. (Germán Correa)

Formamos el MDP y se le informa al Cloro de esta decisión, y el Cloro no quería. El Cloro privilegiaba, por sobre todas las cosas, la unidad del 
Partido Socialista (...) Se arma una delegación para ir a explicarle (a Clodomiro Almeyda) esto que habíamos hecho, y ahí me toca ir en ese viaje, como representante de la Juventud (...) Nos llegó la noticia de que se había formado el Bloque Socialista y eso ya fue como el golpe que convenció al Cloro de que, en realidad, la unidad en esas condiciones no tenía mucho destino, estábamos en posiciones políticas muy distintas. (Jaime Pérez de Arce)

Con el definitivo deslinde respecto al sector "guatón", y creado el MDP como alianza con el PC y el MIR, se consolidó un consenso en el PS en torno a que el enfrentamiento con la dictadura debía ponerse como objetivo su derrocamiento desde una lucha de masas que incluyera elementos insurreccionales, es decir, que asumiera formas violentas. Con esto se ratificaba lo que el PS Almeyda venía llamando desde 1981 "lucha de masas rupturista con perspectiva insurreccional", la que en el marco del MDP y al calor de las protestas nacionales tuvo particular sintonía con la Política de Rebelión Popular de Masas propuesta por los comunistas. ${ }^{57}$ Quedaba sin embargo una duda a resolver ¿hasta qué punto el PS impulsaría la gestión propia de la violencia aguda en la perspectiva de impulsar la insurrección del pueblo? El PC dio señales claras de su posición cuando dio lugar al Frente Patriótico Manuel Rodríguez. El PS, por su lado, sólo llegó a concretar un modesto aparato que realizó acciones puntuales como provocar algunos apagones mediante voladuras de torres: los Destacamentos 5 de abril.

El quiebre del Almeydismo con el CPU en 1983 reforzó una construcción identitaria que separaba el "nosotros" del "otros" en referencia al PS conducido por Núñez. Este último ya no era visto como expresión de la radicalidad, irresponsabilidad o infantilismo revolucionario con el que se representó a Altamirano en la década pasada, sino como imagen negativa de "la renovación" en tanto pérdida del sentido revolucionario del socialismo y ruptura con la izquierda histórica. En ese sentido, los documentos del Almeydismo acusaron al PS Núñez de buscar una alianza excluyente con el centro y sectores de la derecha en la perspectiva de una salida conciliadora, y por tanto, sin una ruptura radical con los cambios políticos, sociales y económicos de la dictadura. A ello se agregó la percepción en torno a que el centrismo político habría intervenido en pos de la disgregación del socialismo y la cristalización de una instancia "socialista" reformista y marcadamente anticomunista ${ }^{58}$, lo que se asociaba a la promoción del aislamiento de quienes se mantengan en la línea ideológica marxista leninista y sostengan una conducta unitaria de toda la izquierda. ${ }^{59}$ Por todo ello, la "renovación" de esos "otros socialistas" se representó como la propuesta de un socialismo sin su componente anti capitalista, con una negación descarada ${ }^{60}$ del marxismo (o su aceptación deslavada de su espíritu crítico revolucionario ${ }^{61}$ ), y sin lo que se consideraban virtudes, fundamentalmente orgánicas, del

\footnotetext{
57 "El partido reafirma su política de lucha de masas rupturista con perspectiva insurreccional como línea orientadora general de nuestro accionar en función de la toma del poder". Ibid. El mismo documento fecha en 1981 la adopción de dicha política, y la relaciona con lineamientos que la izquierda chilena habría adoptado en un encuentro realizado en México durante septiembre de aquel año.

${ }^{58}$ Ibid, 4.

59 idem.

${ }^{60}$ idem.

61 idem
} 
leninismo y su principio de centralismo democrático. En perspectiva histórica, los almeydistas y su militancia juvenil se veían a sí mismos como lorquistas y allendistas, que apostaban por un partido con cohesión leninista que se alejara del "desorden" y el "caudillismo" del PS previo a 1973. Se autopercibían como un partido heredero legítimo de la identidad socialista que reivindicaba el eje de alianza de la UP, que estaba decididamente por la movilización de masas con vistas al derrocamiento del régimen, y que rechazaba negociar con la dictadura y concederle la más mínima legitimidad a su institucionalidad. Por último, se sabían mayoría y acusaban a "los otros" de ser grupos de elite, "pura cúpula", "sin bases sociales".

Toda esta generación, no tanto yo, pero los que eran como mis jefes, los miembros de la enseñanza media para el 73 , ellos quedaron traumados con ese Partido Socialista lleno de fracciones y que terminó como terminó y en cómo terminó el país, (...) esa cuestión está en la cabeza, es trauma, o sea, la idea de que el Partido Socialista tuvo una cuota de responsabilidad tremenda en la derrota del 73. (...) Yo creo que el leninismo en ese momento era la manera de disciplinar a una organización que había sido muy de estructura caudillista. (Ernesto Aguila)

Había una idea intuitiva de que este partido estaba más decidido a lo que nosotros pretendíamos, que era una lucha más o menos frontal contra la dictadura. Parecía que ahí había una decisión mayor de lucha antidictatorial, pensábamos también que ahí había una voluntad clara de articular una política con la izquierda (...) Y también nos llamaba la atención que ahí había un vínculo muy fuerte con lo que era la figura de Carlos Lorca, como uno de los líderes que estuvo en las posiciones correctas en el tema de la UP. (Jaime Fuentealba)

Para el PS Núñez, que desde abril de 1984 pasó a ser conocido como PS Briones, ${ }^{62}$ el almeydismo fue representado básicamente como un socialismo pro comunista, o sea, espurio en términos históricos. Por lo mismo, cuando hablaban de socialistas hablaban de "nosotros", y se referían al otro PS como un bloque más bien comunista. Al igual que lo habían hecho los viejos ataques del altamiranismo al Documento de Marzo, se acusó al almeydismo de "liquidacionista", de buscar fusionar el PS con el PC. A decir de Núñez en una entrevista de 1983: "se ha constituido un bloque comunista en la izquierda, que yo más bien lo llamo bloque de fuerzas definidas como marxistas leninistas, distinto a uno socialista con raíces propias (...) Creo que Almeyda en definitiva con muchos vaivenes, siempre aspiró a estar en un partido que en definitiva apuntara a ser un solo partido con el comunista, como ha sucedido en otros países, donde la posición comunista mantiene un nivel hegemónico". ${ }^{63} \mathrm{Al}$ calor de la

\footnotetext{
${ }^{62}$ En referencia a Carlos Briones, destacado dirigente que había sido el último Ministro el Interior de la UP y que había retornado del exilio. Fue elegido Secretario General del PS de la renovación en un Pleno de la CPU en abril de 1984. En ese momento, un sector quedó disconforme con la elección de dirigencia y ciertos procedimientos asociados a ella (que denunciaron como quebrantamiento de la legalidad partidaria), por lo que se separó de este PS y reconoció como Secretario General a Manuel Mandujano. Núñez volvió a dirigir el PS de la renovación a partir de junio de 1985, en el marco de la fusión con un sector del MAPU Obrero Campesino, y producto de ello, la elección de nueva directiva. Ver: "Entrevista a Carlos Briones: ¿Socialista impenitente o intermitente?” Análisis, 5 al 19 de junio de 1984. Y: "Manuel Mandujano: Posición de Almeyda no es socialista". Hoy, 23 al 29 de mayo de 1984.

${ }^{63}$ En: Entrevista de Sergio Marras a Ricardo Núñez. "Sólo la izquierda con el centro, pueden redemocratizar a Chile". Apsi. 4 al 17 de octubre de 1983.
} 
contingencia de mediados de los años 80, los entonces jóvenes de la renovación percibieron en el almeydismo un voluntarismo basado en consignas más que en reflexiones, una radicalidad sin responsabilidad ni realismo, un leninismo sin raíces profundas en la historia socialista. Como hoy recuerda Enrique Acosta, ex militante de la Federación Juvenil Socialista FJS, referente de la juventud de este socialismo: ${ }^{64}$

Nosotros éramos parte del proceso de renovación socialista y ellos no. (...) Para ellos el Partido Socialista siempre había sido marxista leninista, gran error histórico. (...) En un contexto polar, evidentemente la radicalización es mucho más atractiva para estos jóvenes: "no, aquí no se transa, estamos en la lucha para derrocar la dictadura, y bla bla bla". Entonces nosotros los acusábamos de falta de realismo político, que las cosas eran mucho más complejas. (Enrique Acosta)

Pero el quiebre por el lado del ala moderada y la distinción identitaria de "los Almeyda" frente a la "renovación" no provocó una cohesión partidista que impidiera un nuevo fraccionamiento. De hecho, ya al calor de los eventos de 1983 se había producido una nueva fractura, esta vez por la izquierda y entre la militancia del exilio. Un grupo liderado por Robinson Pérez y Gustavo Ruz acusó a la conducción de Almeyda de girar a la derecha, perseguir a los sectores revolucionarios y querer ganar la hegemonía interna con métodos espurios. ${ }^{65}$ Este grupo logró tener una red de apoyo en el exterior, particularmente en Bélgica (por lo que se le conoció como "corriente de Bruselas") y fueron sancionados bajo acusación de divisionismo e indisciplina.

Un año después, tras una serie de desencuentros, en las reuniones del Quinto Pleno Nacional Clandestino se terminó produciendo la división definitiva entre los comandantes y el resto del almeydismo. Ese resto del partido, a su vez, ya estaba ordenado en torno a dos sub identidades. Por un lado, los que quedan con el nombre de "terceristas", que tenían por líderes a cuadros que sostuvieron la estructura PS clandestina post golpe y luego al almeydismo post 1979, como Germán Correa y Ricardo Solari. Por otro lado, importantes sectores de la militancia fundamentalmente territorial, que se sintieron cercanos al liderazgo de Camilo Escalona así como a otros líderes y cuadros que venían del PS exterior y que habían retornado al país en los años 80 (algunos clandestinamente, como Escalona en 1982), ${ }^{66}$ quienes eran, en ese momento, particularmente cercanos a Clodomiro Almeyda. ${ }^{67}$ Este último grupo, en esos años, comenzaba a representar posturas a la izquierda del tercerismo, es decir con mayor énfasis en la movilización con componentes insurreccionales y con más desconfianza en relación a una convergencia con el centro político y los socialismos de la renovación. De acuerdo a los testimonios recogidos, la JS

\footnotetext{
${ }^{64}$ En contraposición a Juventud Socialista - JS, los jóvenes de la renovación optaron por retomar la antigua sigla FJS. La FJS se constituyó tardíamente en los años ochenta, de modo que la militancia efectiva de este socialismo en los frentes sociales, particularmente en el universitario, se dio principalmente a partir de aquellas estructuras de convergencia socialista (como el Bloque Socialista) en donde el socialismo de Núñez convergió con cuadros del MAPU y la IC.

${ }^{65}$ En: Cuadernos de orientación socialista número 16. Op cit 23.

${ }^{66}$ Álvaro Peralta y Enzo Pistacchio, "Duro de matar”, Santiago, Zig-Zag, 2014.

${ }^{67}$ Entre esos cuadros destacaba el ex secretario nacional de la CUT y ex ministro de agricultura del gobierno de Allende, Rolando Calderón. Otro importante dirigente, particularmente cercano a Almeyda, que retorna en esos años es Guaraní Pereda.
} 
no se involucró mayormente con las dos identidades faccionales mencionadas, por lo menos hasta fines de los años ochenta (como describiremos más adelante), no obstante, durante el V Pleno Clandestino sí se posicionaron en bloque contra "los comandantes".

El deslinde identitario que construyeron los "socialistas Almeyda" respecto a la fractura "comandante", representó a estos últimos como unos "militaristas" o "aparatistas" distanciados del trabajo de masas, que no querían la más mínima alianza con el centro, que promovían el aislamiento vanguardista de la izquierda, que no asumían la heterogeneidad de formas de lucha en función de la política y la movilización de masas, y que daban a las formas de lucha violentas un predominio y autonomía injustificados. Además de aquellas diferencias políticas, se acusaba a los comandantes de aprovechar la presencia que sus cuadros pudieran tener en la estructura orgánica, con fines de materializar una estrategia de control del partido por parte de una facción organizada. O sea, nuevamente los valores leninistas de cohesión partidaria fueron fundamentales a la hora de concretar la expulsión de una facción:

En el PS Almeyda entramos nuevamente en una lucha interna fratricida muy dura, en torno a un grupo que empieza hacer una crítica desde la izquierda. Tiene que ver con el tema del uso o no de la violencia o la lucha armada, desde un grupo que fue conocido como los Comandantes (...) Y finalmente el PS Almeyda expulsa a ese grupo (...) Esto sí tiene un impacto en la Juventud, se pierden sobre todo grupos poblacionales (...) Fue atacado como una desviación a la ultra izquierda. Tampoco era sólo un tema del uso o no de la violencia, sino que también era un grupo que no quería ningún tipo de alianza con el centro político, y era una estrategia muy de derrocamiento de la dictadura, pero con poca infraestructura o con poca capacidad de hacer esto, con poca política, era un aparatismo. (Ernesto Águila)

Esa es una división que, si bien se fundamenta en diferencias políticas, lo más importante es que se nota que es una estructura que empieza a desarrollar una estrategia de toma de poder del Partido, empiezan a ocurrir cosas raras que empiezan a generar suspicacias en el resto. De cosas que no llegaban, de cosas que se hacían sin preguntar; se ve como un grupo de poder que se empieza a orquestar, paralelamente a la estructura. Y piensa tú que en ese tiempo nosotros veníamos de la cultura leninista, de la cultura del partido con centralismo democrático, donde estas hueás no existían y eran profundamente condenadas". (Jaime Pérez de Arce)

Estas miradas fueron expresadas en las resoluciones del $\mathrm{V}$ pleno Nacional Clandestino, en el sentido de enfatizar que la etapa insurreccional, en tanto perspectiva, debía incorporarse paulatinamente según la maduración de la lucha de masas por la democracia, pues: "no es posible hacer saltar a las masas etapas de aprendizaje de lucha, empujándolas voluntaristamente a que se insurreccionen desde ya (...) no es por tanto el discurso estrategista ni militarista el que atraerá a las masas" ${ }^{68}$ Los "comandantes", por su parte, consideraban que el partido no tomaba en serio su opción insurreccional, dejándola sólo como un discurso sin ninguna expresión concreta, lo que significaría, a la vez, que el

\footnotetext{
${ }^{68}$ En: Resoluciones Políticas del V Pleno Nacional Clandestino del Partido Socialista de Chile. Agosto, 1984, p 10.
} 
PS perdería sintonía con los aliados del MDP y se acercaría a la izquierda más centrista. Para el sector liderado por Gutiérrez, había que organizar la insurrección en la perspectiva de materializar una huelga general e introducir elementos de violencia armada en el enfrentamiento de la protesta. En esa línea, una de las primeras medidas tras el quiebre fue el intento de construir milicias en la organización poblacional, las llamadas "milicias populares allendistas":

Nosotros, lo que estábamos diciendo, era que había que trabajar la perspectiva de una huelga general, esa era nuestra política. Y esa política debía ser complementada con el trabajo poblacional en lo que se denominó "el cordón", para rememorar los antiguos cordones, el Cordón Américo Vespucio, la formación de milicias, las milicias populares allendistas que tuvieron un nivel de inicio de instrucción armada. (Eduardo Gutiérrez)

A nivel de los pronunciamientos oficiales del partido, se repitieron los adjetivos con que el lorquismo y sus herederos solían identificar a la disidencia radical: infantilismo revolucionario, sectarismo, indisciplina, irresponsabilidad, voluntarismo; todo ello en contraposición a los valores de la responsabilidad, la racionalidad, la cohesión partidista y el centralismo democrático expresadas en "un partido homogéneo y serio, que no permite el desarrollo de fracciones ni de querellas subalternas por el poder en su seno". ${ }^{9}$ Con el mismo tono, en octubre de 1984, sin dar todavía nombres ni detalles de la crisis, Clodomiro Almeyda se refirió implícitamente a la pugna con "los comandantes" en una entrevista al periódico del partido Unidad y Lucha:

Las desviaciones sectario-dogmáticas constituyen un aliado privilegiado y además, insidioso, de las fuerzas conservadoras y reaccionarias instaladas en el seno, precisamente, del pueblo. De manera que la erradicación de esta desviación política - que con razón la calificó Lenin como "la enfermedad infantil del comunismo", es decir, en nuestro lenguaje actual, de los revolucionarios - que expresa el retraso del desarrollo de la conciencia política popular, constituye una tarea fundamental. En el proceso por derrotar tal desviación sectaria, el Quinto Pleno Nacional del Partido ha constituido un avance decisivo." $" 70$

Esta vez la ruptura había sido mucho más compleja para la militancia que la salida de Stuardo y Soto, y claramente, más traumática que la crisis faccional que tuvo el almeydismo con la corriente de Bruselas. Los llamados "comandantes" sí tenían presencia importante a nivel nacional en el PS, contaban con un líder destacado como Gutiérrez y, según se establece en los testimonios, controlaban gran parte de las informaciones orgánicas necesarias para el funcionamiento del partido clandestino a nivel nacional, es decir, tenían una incidencia y control sobre lo que la militancia llamaba "el frente interno",

\footnotetext{
${ }^{69}$ Ibid 23.

${ }^{70}$ En: "Entrevista a Clodomiro Almeyda: El paro nacional es el eje ordenador de la movilización social". Unidad y Lucha número 76, octubre de 1984.
} 
lo que significó una larga lucha del almeydismo por retomar los vínculos nacionales del partido clandestino.

Materializado el quiebre, los comandantes se denominaron a sí mismos "PS dirección colectiva". Aunque como corriente interna habían concitado importantes apoyos, estos disminuyeron cuando se produjo la ruptura y ellos quedaron como disidentes. Por un lado, la propia cultura militante leninista les jugó en contra, y los militantes mayoritariamente siguieron a la dirección oficial. Por otro lado, el hecho de romper con uno de los dos PS más reconocidos internacionalmente les significó perder valiosos apoyos en recursos provenientes de la solidaridad internacional, lo que limitó sus capacidades orgánicas. En su práctica política hicieron todo lo posible por mantenerse dentro del MDP, del cual se sentían legítimos miembros y promotores. Más aún, conscientes de que su política de potenciar la insurrección era particularmente similar a la que defendían los comunistas, suponían que, por lo mismo, estarían más en sintonía con esta alianza que lo que estaba la propia dirección de Almeyda. Sin embargo, prontamente comprendieron que el PS Almeyda controlaba las relaciones del eje PS - PC, por lo que resintieron lo que consideraron una marginación a nivel cupular y reivindicaron lo que definieron como una cotidiana inserción a nivel de las bases del MDP. ${ }^{71}$ Dado el nivel de disgregación de las fuerzas socialistas, los comandantes no confluyeron en unidad orgánica con otros PS con los que compartían lecturas políticas similares. De hecho, aunque hubo acercamientos con la corriente de Bruselas, siguieron operando por separado de lo que fue la expresión partidista de esta última: el "PS Salvador Allende".

En su versión de XXIV congreso, realizado en 1985, el almeydismo refrendó la legitimidad de "todas las formas de lucha", y su "lucha de masas rupturista con perspectiva insurreccional"72. Ad portas de 1986, se reforzó la alianza con el PC y su Política de Rebelión Popular de Masas, lo que provocó aún más distanciamiento respecto a un socialismo renovado que aparecía definitivamente más dispuesto a establecer alianzas con la DC que con el MDP. Al menos así se iba haciendo notar tanto en las acciones de la Alianza Democrática como en los frentes sociales, en donde las posiciones respecto al uso de la violencia marcaron los deslindes en las divisiones de la oposición.

El año 1986 determinó la derrota de las apuestas por el derrocamiento de Pinochet por vía insurreccional. Los eventos del hallazgo de armas en Carrizal y el frustrado tiranicidio del FPMR remecieron al MDP, marcando un giro del PS Almeyda y un aislamiento político del PC. La entrada clandestina al país de Clodomiro Almeyda y su entrega a los tribunales a principios de 1987, fue parte de la puesta en marcha de este viraje socialista, ya que, a partir de entonces, este líder, aun en condición de preso o relegado, fue

\footnotetext{
${ }^{71}$ En 1985 Eduardo Gutiérrez declaraba: "Si bien por circunstancias bastante puntuales no participamos en el Consejo Nacional del MDP, no hemos sido marginados como usted señala. Nuestra inserción y participación es activa y combatiente en los consejos de base del movimiento". En: "Eduardo Gutiérrez: queremos un acuerdo, pero un acuerdo popular". Análisis. 22 al 28 de octubre de 1985.

${ }^{72}$ Las resoluciones del XXIV congreso almeydista ratifican la línea denominada "Lucha unitaria y democrática de masas, de carácter rupturista y con perspectiva insurreccional", que incluía la validez de "todas las formas de lucha que contribuyan a consolidar y potenciar el movimiento de masas". La idea era promover el derrocamiento de la dictadura por vía de la movilización de masas y en el marco de una unidad opositora con base en un "gran acuerdo democrático". No obstante esto último, se estimaba que lo prioritario para esa unidad amplia era resguardar la unidad de la izquierda radicada en el MDP. Lo militar era subordinado a la lucha de masas y se relacionaba con dos aspectos: "el desarrollo de la autodefensa de las masas y la aplicación de una política hacia las fuerzas armadas, orientada a debilitarlas y provocar su colapso". Las citas textuales en: Resoluciones del 24 congreso del Partido Socialista de Chile. Agosto 1985.
} 
activo en establecer conversaciones tanto con los dirigentes de su partido como con los líderes de "la renovación" y la Democracia Cristiana, en la perspectiva de definir estrategias para una salida pactada. En el mismo 1987, en junio, se creó un nuevo referente de izquierda que amplió las alianzas del MDP pues sumaba a la Izquierda Cristiana y al MAPU: la Izquierda Unida, ampliación que también implicaba cierta moderación y acercamiento con sectores renovados de la convergencia socialista. Para el almeydismo, la consecuencia histórica de todo ello, fue el llamado a inscribirse en los registros electorales, la participación en el plebiscito de 1988, la unificación socialista y la creación de la Concertación de Partidos por la Democracia que gobernará Chile a partir de 1990. Entonces, los ex socios del MDP, miristas y comunistas, quedaron excluidos de la nueva coalición, ${ }^{73}$ y pese a los esfuerzos que se hicieron, también de la política parlamentaria. ${ }^{74} \mathrm{El}$ socialismo retomó, ya bajo unidad orgánica, su característica vida de "tendencias". Eso sí, ello se dio a partir de un consenso que situó a "la renovación" como triunfadora en lo doctrinario, siendo sus concepciones las que quedaron plasmadas en la nueva Declaración de Principios, no así las valoraciones orgánicas e ideológicas del marxismo-leninismo que hasta hace poco eran reivindicadas por la tradición almeydista.

\section{Terceristas, generacionales y escalonistas. Las corrientes del almeydismo en el proceso de unidad socialista y el contexto de la transición política}

Como se dijo, el quiebre con los "comandantes", lejos de terminar con dinámicas faccionales, más bien las reconfiguró, algo que, de acuerdo a algunos testimonios, fue inmediatamente advertido por las dirigencias. Al respecto, Germán Correa recuerda un intercambio que tuvo con Ricardo Solari:

Solari, el día que echamos a los comandantes me dijo: esto es malo pa nosotros - ¿pa' quienes? - pa ti, pa mí... pa nosotros, malo - por qué, le dije yo - porque ahora que echamos a los comandantes, Camilo va a ser el que se va erguir como representante de la izquierda y nosotros vamos a ser representantes del otro lado - me dijo - y eso es malo. (Germán Correa)

Efectivamente, hacia fines de los ochenta, y ad portas de la unidad socialista, estos subgrupos de características faccionales ya habían copado la totalidad militante, al punto que la Juventud Socialista, que en principio había estado al margen de dichas identidades, se reordenó en función de ellas. Entonces, buena parte de los liderazgos que venían de, o estaban en el movimiento universitario, se vincularon al tercerismo, teniendo por líderes a históricos dirigentes de la JS en dictadura como Ernesto Águila, Alejandro Goic o Jaime Pérez de Arce, así como a destacados dirigentes universitarios como Jaime Andrade. Por otro lado, sectores significativos provenientes del movimiento estudiantil secundario,

\footnotetext{
${ }^{73}$ Corresponde precisar que, aunque el MIR y el PC no entraron a la Concertación, hubo militantes que rompieron con dichos partidos y se sumaron al PS o al Partido por la Democracia PPD.

${ }^{74}$ El esfuerzo más concreto fue la creación, en noviembre de 1988, de un partido instrumental de la izquierda: el Partido Amplio de Izquierda Socialista PAIS, que participó en las elecciones parlamentarias de 1989, pero sin lograr que entraran al parlamento cuadros del PC y del MIR.
} 
juvenil territorial y fuertes en la JS del momento, se asociaron a las redes tendenciales que construía Camilo Escalona y que recibieron el nombre genérico de "la Franja".

Los terceristas venían de poner más acento en el "acuerdo democrático amplio" que en lo insurreccional, por lo que desconfiaron de experiencias como los Destacamentos 5 de Abril, aunque Almeyda los incluyó en su dirección. ${ }^{75}$ A decir de Ernesto Águila "siempre vieron una salida más política de la dictadura que una salida más insurreccional". En la perspectiva de Jaime Pérez de Arce, su auge se debe entender en el contexto de la pérdida de hegemonía de la mirada comunista en la izquierda luego que el año 1986, calificado por el PC como "decisivo", no trajo el fin de la dictadura: "tenían un poco que ver con cómo te descolgabas del hecho de que el año decisivo no lo había sido para las fuerzas populares". En ese contexto, los terceristas fueron los más entusiastas con el giro de 1987 que acercó definitivamente el PS al centro político, en la perspectiva de construir un gobierno posdictatorial. También les acomodaba más el marco ideológico cultural de la renovación, así como la crítica a los socialismos reales que se derrumbaban en Europa del Este. ${ }^{76}$ La Franja, fuerte en el ámbito poblacional, se manifestó mucho más identificada con el MDP y el eje PC - PS, así como más crítica del reconocimiento a la institucionalidad pinochetista que a su juicio involucraba una salida pactada para terminar con la dictadura. De tal modo, si bien siguieron lealmente a Almeyda, mantuvieron una distancia identitaria con el viraje que terminó consagrando a la Concertación de Partidos por la Democracia como alianza de gobierno. Vinculado a La Franja estuvo un sector de la JS autodenominado La Generacional, nombre que refería al nexo etario y experiencial de quienes habían sido militantes juveniles durante la segunda mitad de los 80, es decir, se trataba de una militancia que destacaba como elemento de identidad su distinción con quienes tenían más edad y habían reconstruido la JS desde una historia militante que se remontaba hasta la segunda mitad de los setentas. O sea, si lo queremos ver en términos etarios, hacia 1987 se trataba, en general, de jóvenes de 15 a 25 años, que por sus experiencias, se percibían como generacionalmente diferentes a sus compañeros y líderes de 25 a 35 años. ${ }^{77}$ La Generacional tenía fuerte presencia en la militancia territorial, en el movimiento estudiantil secundario, y también en el movimiento universitario. En general, tanto La Generacional como La Franja desconfiaban de la renovación socialista y cultivaron la idea de ser una identidad atada al lenguaje y a los símbolos del socialismo que parecían desaparecer en la carga cultural de la renovación. El puño cerrado, la palabra "pueblo", el imaginario asociado a la revolución latinoamericana y a la clase obrera persistieron en este sector, mientras que los terceristas, al igual que los renovados, ya recurrían a términos como "la ciudadanía" y "la gente" en un marco de referencias definitivamente post guerra fría. De

\footnotetext{
75 Jaime Pérez de Arce cuenta que aunque cuadros del tercerismo se opusieron a la idea de crear el Destacamento, una vez que la iniciativa se aprobó, Almeyda incluyó a dirigentes terceristas en la comisión encargada de su materialización y dirección.

${ }^{76}$ Como comenta Ernesto Águila, los últimos conflictos de la Guerra Fría también fueron materia de deslinde entre unos terceristas que se negaban a apoyar la intervención de URSS en Afganistán y sus oponentes tendenciales que deseaban firmar una declaración pro soviética.

${ }^{77}$ Naturalmente el corte etario no tiene una correspondencia absoluta y exacta con el alineamiento político de la JS, pero sirve para entender la contrucción identitaria de referencia etario - generacional que asume este grupo en particular. Pensemos que en 1987 los líderes del tercerismo en la JS eran Ernesto Águila (25 años), Jaime Pérez de Arce (32 años) y Alejandro Goic (30 años), mientras en La Generacional estaban, entre otros, Jaime Fuentealba (22 años), Arturo Barrios (20 años) y Gonzalo Durán (19 años).
} 
algún modo, la apuesta de estos últimos era adaptarse a los "signos de los tiempos", desarrollando una modernización discursiva y estética como respuesta a fenómenos que la propia historia ponía en el tapete: la caída de los socialismos reales y la crisis mundial de las izquierdas.

Yo creo que la juventud socialista mantuvo una tendencia o una opinión adentro del PS hasta el 87 más o menos. (Entonces) comienza a vivirse una separación de opiniones políticas en la cual un sector, que después adhiere claramente al tercerismo, impulsa con mucha más fuerza la unidad socialista juvenil, la política de inscripción electoral, la política de unidad con la Democracia Cristiana. Yo no diría que el otro sector no adhirió de alguna forma a todas esas políticas en distinto momento, pero yo creo que le era mucho más difícil, era mucho más desgarrador. Ahí ya se comienza a vivir una bifurcación, y (surge) este sector que forma el grupo "generacional". (Ernesto Águila)

En la elección del Comité Central del año 87, o del 88, no sé bien, fue una lista que se denominó Generacional porque agrupaba a un conjunto de actores que teníamos o proveníamos, más o menos, de una misma historia, más o menos de una misma generación. Piensa que la JS, hasta el año 89 o 88, había desde los 17 años hasta los 35. (Gonzalo Durán)

El hecho de que se avanzara en la elección democrática de los cargos partidarios ayudó a un mayor perfilamiento de las tendencias en el almeydismo, pues en los eventos de la Juventud y el partido se agrupaban y coordinaban las corrientes, instalándose una cotidianidad en torno a sus deslindes: reuniones por separado, acuerdos, documentos, una representación y un discurso identitario respecto a un "nosotros" y un "otros" tendencial. El siguiente relato de Arturo Barrios, entonces militante y dirigente de la JS, grafica el descubrimiento de la vida de corrientes por parte de un militante que inmediatamente internaliza las lógicas inscritas en ella. Aquí se presenta una dimensión no menor del fenómeno, que es que la tendencia, además de configurarse en torno a las consideraciones políticas, se superpone a los vínculos cotidianos del militante: sus amistades, sus espacios, el imaginario identitario respecto a quienes son sus más cercanos y con quienes comparte trayectoria:

A mí me invitaron a participar de una Conferencia, ya como Presidente del Pedagógico el 88 o el 87 (...) Y ahí nos juntamos, estaba Ernesto Águila, Jaime Pérez de Arce, Jaime Andrade, está la María Eliana Arntz, e íbamos con estos hueones y salimos y nos fuimos a tomar algo a la casa de uno de ellos. Y dicen: puta, perdimos, perdimos. Y yo decía (pensaba): chucha, qué huea perdimos. Y decían: puta, perdimos, nos sacaron la chucha. Y yo: sí po, perdimos. Yo tratando de hacerme como el que entendía. Y ahí conversando, me acuerdo que era en el Parque Forestal. Entonces, yo salgo, y pensaba: puta qué hueá perdimos. Seré tan hueón que no entiendo lo que perdimos. Y me voy caminando y me encuentro con Fisher (apodo de Jaime Fuentealba) (...) Y me agarra el Fisher: hola, Negrito. Hola, compadre. Y me dice: ganamos, ganamos, qué buena. Y me dice: vamos, porque nos vamos a juntar con los compañeros. Llego a 
la otra reunión y ahí todos los hueones diciendo que ganamos, estaba el Anselmo Cádiz, estaba el Raúl Álvarez, el "Llanquihue", el Dionisio, y todos diciendo ganamos y me preguntaban a mí: ¿ganamos Negro? Y yo les decía: sí po, ganamos. Enteramente oportunista, cómo iba a decir: no, si perdimos. Y entonces yo dije: chucha acá está pasando una hueá que yo no entiendo, algunos hueones me dicen que perdimos y otros hueones me dicen que ganamos. Entonces ahí yo me sinceré con el Fisher y le dije: oye, hueón, sabís qué, yo necesito que me expliques esta hueá, porque yo vengo de una reunión... Y me dice: ¿de dónde venís? Luego de explicarle, me comenta: ah, ya, esa hueá es el Tercerismo, Negro. ¿Y esos hueones qué onda? (pregunto). No, (me dice) son más amarillos que nosotros, nosotros somos los hueones de izquierda, el Dionisio y todos nosotros somos "La Generacional" y estamos construyendo una hueá con Camilo Escalona. En ese tiempo el Escalona era una especie de Manuel Rodríguez de la hueá, cachai. Vos llegabas a Beauchef (calle de la escuela de ingeniería) y te decían oye, por aquí pasó Camilo Escalona y nunca lo podías ver, clandestino. (...) Entonces, yo le dije, si yo soy un hueón de izquierda, yo soy del Pedagógico. Y me dice: sí, po, si nosotros te contamos dentro de nosotros. Y ahí yo dije: ya po, ganamos entonces. (Arturo Barrios- PS Almeyda, Generacional, La Franja).

En 1989 la actividad de unificación comenzó con la JS fusionándose con la FJS en lo que se denominó Unión de Jóvenes Socialistas UJS. En diciembre del mismo año se anunció la definitiva unificación del PS de la renovación (desde mayo de 1989 dirigido por Jorge Arrate) y el PS Almeyda, dándose por concluida la división surgida en 1979. A partir de ese momento se unieron además al PS sectores del MAPU, de la IC, de un desmembrado MIR, hasta cuadros disidentes del PC, todos los cuales confluirán en el Congreso de Unidad Salvador Allende celebrado en noviembre de 1990.

Tanto la militancia "histórica" como aquella proveniente de otros partidos, comprendió tempranamente que para insertarse en el funcionamiento del PS unificado debía estar adscrita a alguna de sus corrientes. De tal modo, como una lógica particularmente persistente, el PS unificado volvió a ser un partido de facciones más o menos visibles, más o menos organizadas. Lo que había sido el almeydismo presentaba, como ya se mencionó, al menos dos grandes grupos. La renovación, por su parte, tampoco entraba a la unificación en bloque, y sus dos mayores líderes, Núñez y Arrate, comenzaron a representar sensibilidades diferentes. ${ }^{78}$ Aunque se acordó salomónicamente que la presidencia del partido se alternaría entre Arrate y Núñez (un año para cada uno), y que Clodomiro Almeyda asumiría un cargo honorario como cabeza de un "Consejo Superior", sí hubo en el congreso de 1990 una medición electoral importante en la elección del Comité Central. ${ }^{79}$ Aunque a esa elección se presentaron seis listas, tres de ellas fueron las que

\footnotetext{
${ }^{78}$ Según algunos analistas, mientras el "arratismo" se manifestaba más cercano a la tradición del socialismo chileno, el "nuñismo" optaba por conectarse identitariamente con una socialdemocracia pragmática europea. Ver: Ricardo Gamboa y Rodrigo Salcedo, "El faccionalismo en el partido socialista de Chile (1990 - 2006): Características y efectos políticos en sus procesos de toma de decisión", Revista de Ciencia Política, volumen 29, número 3, Pontificia Universidad Católica de Chile, Instituto de Ciencia Política, Santiago, 2009, 667-692.

${ }^{79}$ Ver: "Partido Socialista. Salomón reina en la cúpula". Análisis, 17 al 23 de septiembre de 1990.
} 
concentraron las corrientes fundamentales del socialismo unificado: la lista "Alternativa y Socialismo" en torno a las figuras de Núñez, Ricardo Lagos, Marcelo Schilling, Hernán Vodanovic, Sergio Bitar y buena parte de la renovación de la convergencia socialista; la lista "Unidad y Renovación" que representaba la alianza de los renovados cercanos a Arrate y los terceristas del almeydismo, es decir, a cuadros como el propio Arrate, Germán Correa, Enrique Correa, Isabel Allende y Ricardo Solari; y por último, la lista "Democracia y Socialismo", que reunía el espectro socialista más disconforme con el giro hacia el centro y la fractura de la izquierda histórica, cuyo líder indiscutido era Camilo Escalona y que contaba con el apoyo de figuras importantes del almeydismo como Manuel Almeyda, Mario Palestro y Rolando Calderón. ${ }^{80}$ Los votos favorecieron la opción que los medios calificaron como "ortodoxa", es decir, a "Democracia y Socialismo", que obtuvo más del $33 \%$ y tuvo en Camilo Escalona la más alta votación a nivel nacional. ${ }^{81}$ En tal contexto, el tercerismo operó como corriente bisagra, y buscó acuerdos en los que Arrate jugó un rol protagónico al dar señales concretas al grupo que aparecía como mayoritario. La más trascendente de esas señales fue apoyar el recelo almeydista respecto al partido instrumental que con fines electorales había creado la convergencia socialista y algunos cuadros de adscripción liberal en 1989: el Partido Por la Democracia, PPD. En tal sentido, el arratismo y el tercerismo se sumaron al escalonismo en el rechazo a una condición de doble militancia PS - PPD. De esta forma, uno de los efectos concretos que tuvo la medición de fuerzas al interior del socialismo, fue que se diera un plazo de dos años a dicha doble militancia para que optara entre uno u otro partido, lo que derivó, a la postre, en la salida de cuadros que no se acostumbraron a lidiar con el pluralismo de izquierdas del nuevo PS y optaron por mantener residencia en el PPD. ${ }^{82}$

Todavía existe el debate sobre la posición del propio Clodomiro Almeyda en tales deslindes faccionales del otrora almeydismo. ${ }^{83}$ No obstante, hay cierto consenso en asumir que el giro definitivo del PS hacia abrazar la transición según las opciones que promovió la Concertación de Partidos por la Democracia, fue un proceso conducido por dicho líder tras su retorno al país. ${ }^{84}$ En definitiva, esa vez, los almeydistas sí se cohesionaron en torno a la

\footnotetext{
${ }^{80}$ A esos históricos almeydistas se sumarían viejos dirigentes izquierdistas del PS retornados del exilio como Adonis Sepúlveda.

${ }^{81}$ La prensa también menciona que, dado que una lista de identidad juvenil y otra territorial eran cercanas a esta corriente, el apoyo efectivo del sector "escalonista” superaba el 40\%. Ver: "Elecciones en el PS: ¿Fin a la doble militancia?”, Análisis, 12 al 18 de noviembre de 1990.

${ }^{82}$ No fueron pocos los militantes provenientes del PS Núñez y los partidos de la convergencia socialista que optaron por quedarse en el PPD. En el caso de los jóvenes, es claro que buena parte de la militancia universitaria del viejo Bloque Socialista optó por el PPD, como el caso de los dirigentes Carolina Tohá, Ricardo Brodsky y Guido Girardi.

${ }^{83}$ En 1990 la prensa describía a Almeyda en una posición autónoma de terceristas y escalonistas, rodeado de sus colaboradores más cercanos con quienes compartió el exilio: Rolando Calderón, Hernán del Canto y María Elena Carrera. Ver: "A dónde va el PS", Hoy, 30 de abril al 6 de mayo de 1990.

${ }^{84}$ Una opción particularmente llamativa del almeydismo, y que se atribuye al liderazgo de Almeyda, fue dar tempranas señales de un apoyo a Aylwin como candidato de la Concertación a la presidencia (Almeyda declaró en Europa y en Chile que Aylwin era "el candidato con más posibilidades" y que el PS podría apoyarlo, para luego oficializar el apoyo en junio de 1989), con anterioridad al socialismo renovado, cuando todavía se discutían otras alternativas, y a contrapelo de las fuertes resistencias que su nombre tenía entre los socialistas (dado su pasado de fuerte opositor a Allende y su conocido respaldo al golpe de Estado en 1973). Varios testimonios, entre ellos los de Ricardo Núñez, adjudican a Almeyda, en acuerdo con los terceristas, las tempranas señales de apoyo a la candidatura de Aylwin. Ver: Fernández Joaquín, Góngora Álvaro, Arancibia Patricia. "Ricardo Núñez, trayectoria...". Ver también: "Clodomiro Almeyda: Hay carne, hay evidencias, hay color", Apsi, 10 al 16 de abril, 1989. Ver “A pesar de todo...”, Análisis, 26 de junio al 2 de julio. 1989.
} 
apuesta concertacionista de Clodomiro Almeyda, con mayor o menor entusiasmo, y esos niveles de entusiasmo serían factores de peso para las nuevas distinciones faccionales. ${ }^{85}$

Aun cuando los sectores que reivindicaban la herencia marxista leninista y la alianza histórica con el PC obtuvieron un triunfo importante en la citada elección de Comité Central, con el tiempo fue quedando claro que el imaginario de la renovación tomaba fuerza y se imponía. Esto tenía un contexto nacional definido por la irrupción de la Concertación y el aislamiento del PC, pero también un contexto mundial marcado por el derrumbe del bloque soviético, representado en el derrumbe físico del muro de Berlín. Los almeydistas apelaron entonces a su diferencia histórica con el PC en el sentido de no haber sido un partido homogéneamente acrítico con la URSS, a su singularidad latinoamericana, y a su tradición democrática, todo ello como modo de apreciar en la renovación una continuidad con un tronco socialista en común. De tal manera, el discurso renovador y la propia palabra renovación, que tanta desconfianza había despertado en el almeydismo, pasaban a ser promovidas y aceptadas como virtud socialista a proyectarse en la unidad. ${ }^{86}$

En 1991, el triunfo de Jaime Fuentealba (conocido por su apodo "Fisher") y La Generacional en las elecciones de directiva de la Juventud, significó que pronto se desechara el nombre UJS y se retornara a la sigla JS. Fue ese quizás un último triunfo simbólico de los que aun mantenían cierto anclaje de identidad en el "lorquismo", las categorías marxistas leninistas, y la vieja unidad de la izquierda.

\section{Conclusión: el PS, la persistencia faccional y la posdictadura}

Consolidada la unidad socialista, aquellos que en buena medida eran los triunfadores al imponer su revisionismo político y doctrinario, es decir, los "renovados", quedaron notoriamente bien posicionados en el gobierno de Aylwin junto con todo el mundo de la convergencia socialista, particularmente ex MAPU. El "tercerismo", por su parte, fue la corriente mejor instalada entre los otrora almeydistas, mientras La Franja, convertida luego en "Nueva Izquierda", quedó relegada del protagonismo gubernamental. Tales tendencias establecieron alianzas y oposiciones entre sí, disputando puestos de dirección partidaria, cupos para candidaturas a cargos de elección popular, y la influencia de cada sector al interior de la Concertación y el poder ejecutivo. Las disputas traerán nuevas realineaciones y la emergencia de nuevas corrientes.

Paralelamente, quedó claro que las generaciones protagonistas de la dinámica gubernamental de la transición fueron fundamentalmente las que ya eran protagonistas antes de 1973, incluyendo la generación juvenil marcada por el golpe de Estado. Por lo mismo, quedó en gran medida relegada de la primera línea aquella generación que socializó como juventud partidista durante la dictadura. Estos cuadros, sin duda, se sumaron a una lógica faccional que fue transversal y que llegó a la propia juventud socialista.

\footnotetext{
${ }^{85}$ El menor entusiasmo de los Escalonistas representa para muchos un distanciamiento concreto entre Almeyda y el sector de Escalona. Testimonios, tanto de terceristas como de escalonistas de la época, hablan incluso de una mayor cercanía de Almeyda con las políticas de los terceristas y su involucramiento con el gobierno de Aylwin.

${ }^{86}$ Ya poco antes de la caída del muro de Berlín, Rolando Calderón sostenía en 1989: "la unidad socialista va a aportar a la renovación de la izquierda. Una izquierda de mayoría renovada, una izquierda no dogmática que asuma los cambios y la verdadera realidad del país". En: “Rolando Calderón: Queremos la fusión del PS Almeyda y el PS Núñez en 1989”. Apsi, 16 al 22 de enero de 1989.
} 
Como lo sostienen algunos artículos, ${ }^{87}$ uno de ellos vinculado con la presente investigación, ${ }^{88}$ los deslindamientos entre corrientes del PS fueron cada vez menos marcados por diferenciaciones político-programáticas o político-ideológicas, y mucho más determinados por aquella dimensión de la política asociada a la distribución del poder y las funciones al interior de la orgánica militante. Es decir, si bien por cuestiones identitarias (así como lealtades con base en historias compartidas), quedaron en pie buena parte de los subgrupos configurados en 1990 (que derivaban de los faccionalismos previos), lo cierto es que se fueron perfilando como formas de agrupamiento funcionales a la operatividad del partido y bases de la práctica militante, pero vaciadas, en gran medida, de aquel tipo de clivajes ideológicos y estratégicos que habían caracterizado el periodo que va de 1979 a 1990. En ese contexto, no es de extrañar que desde el propio lenguaje partidario cambió la forma de referirse a los grupos intrapartidarios, y la palabra "tendencia" fue remplazada por otra que definió básicamente el hecho del agrupamiento para operar: "el lote". Desde "los lotes" se distribuía el poder, las candidaturas a cargos de representación popular, los cargos de gobierno, al punto que muchos socialistas asumieron la "imposibilidad" de militar sin "lotearse" o "ser loteado".

Claramente, este artículo no ha tratado sobre este proceso, sino sobre el periodo previo, cuando las preguntas sobre cómo enfrentar la dictadura, con quienes aliarse para ello, y desde qué valoraciones ideológicas hacerlo, determinaron el persistente faccionalismo socialista. Ahí se forjó una nomenclatura faccional que nos llega hasta el día de hoy de un modo mucho más incomprensible para quienes no son militantes socialistas. Porque si en 1989 cualquier persona cercana a la cultura de izquierda podía entender las diferencias entre renovados y almeydistas, o entre un naciente tercerismo y el escalonismo, hacia fines de la década de 1990 el faccionalismo socialista fue perfilándose como un tema del que sólo eran entendidos los socialistas. Pasó a ser "la interna", como tema de conocimiento, identidad, y a veces pasión de "los de adentro", pero como dimensión totalmente desconocida e incomprensible para los externos, o sea, para "la ciudadanía" o "el pueblo".

Sin duda, la posdictadura reflejó que el PS había cambiado. Pero tales cambios deben ser entendidos a la luz de las profundas transformaciones de la sociedad chilena. La dictadura, lejos de ser un paréntesis histórico, fue una real revolución que alteró el modelo de desarrollo y la institucionalidad política. Siendo ya otro el lugar, las lógicas y las posibilidades otorgadas a la lucha política y su vínculo con la sociedad, el PS siguió siendo un partido de facciones, pero cambiaron radicalmente los sentidos y contenidos que caracterizaron dicho faccionalismo. Se abre acá un ámbito para nuevas investigaciones que relacionen el cambio en los sentidos del faccionalismo en los partidos políticos chilenos con los cambios en la política a nivel general, esto es, el estudio de la relación entre las dinámicas internas de los partidos y los vínculos estructurales entre política, Estado, economía y sociedad. De cualquier modo, una mirada atenta a la historia política reciente tendrá que fijar su atención en el Partido Socialista de Chile, a veces tan difícil de conocer, siempre complejo, pero tan importante para la historia de la izquierda nacional.

\footnotetext{
${ }^{87}$ Ricardo Gamboa y Rodrigo Salcedo, "El faccionalismo en el partido socialista de Chile..."

88 Víctor Muñoz Tamayo, "El Partido Socialista de Chile y la presente cultura de facciones. Un enfoque histórico generacional (1973 - 2015)”, Izquierdas, número 26. USACH - IDEA, Santiago, 2016.
} 


\section{Bibliografía citada.}

Altamirano, Carlos. Dialéctica de la derrota, México, Siglo XXl, 1977.

Álvarez, Rolando y Loyola, Manuel (editores). Un trébol de cuatro hojas. Las Juventudes Comunistas de Chile en el siglo XX, Santiago de Chile, Ariadna, 2014.

Arrate, Jorge; Rojas, Eduardo. Memoria de la Izquierda Chilena, tomo dos, Santiago, Javier Vergara editor, 2003.

Azocar, Juan. Lorca. Vida de un socialista ejemplar, Santiago de Chile, Radio Universidad de Chile, 2015.

Casals, Marcelo. El alba de una revolución. La izquierda y el proceso de construcción estratégica de la "vía chilena al socialismo", Santiago, Lom, 2010.

Drake, Paul. Socialismo y populismo. Chile 1936 - 1973, Valparaíso, Instituto de Historia UCV, 1992.

Fernández, Joaquín; Góngora, Álvaro; Arancibia, Patricia; Ricardo Núñez. Trayectoria de un socialista de nuestros tiempos, Santiago, Universidad Finis Terrae, 2013.

Gamboa, Ricardo; Salcedo, Rodrigo. "El faccionalismo en el partido socialista de Chile (1990 2006): Características y efectos políticos en sus procesos de toma de decisión", Revista de Ciencia Política, volumen 29, número 3, Santiago, Pontificia Universidad Católica de Chile Instituto de Ciencia Política, 2009.

Garcés, Joan. Allende y la experiencia chilena. Las armas de la política, Santiago de Chile, Hueders, 2013.

Gutiérrez, Eduardo. Ciudades en las sombras (una historia no oficial del Partido Socialista de Chile), Santiago, Editores Asociados, 2010.

Jobet, Julio Cesar. Historia del Partido Socialista de Chile, Santiago, Documentas, 1987.

Muñoz Tamayo, Víctor. "El Partido Socialista de Chile y la presente cultura de facciones. Un enfoque histórico generacional (1973 - 2015)", Izquierdas, número 26, Santiago, USACH - IDEA, 2016.

Muñoz Tamayo, Víctor. Generaciones. Juventud universitaria e izquierdas políticas en Chile y México, Santiago de Chile, Lom, 2011.

Ortiz, Edison. El socialismo chileno de Allende a Bachelet. (1973 - 2005), Santiago, Alerce Talleres Gráficos, 2007.

Pairicán, Fernando. "La gran crisis: las Juventudes Comunistas de Chile defendiendo su identidad en tiempos de transición y renovación democrática 1989 - 1992*, Izquierdas, número 30, Santiago de Chile, IDEA - UACH, 2016.

Palieraki, Eugenia. ¡La revolución ya viene! El MIR chileno en los años sesenta, Santiago, LOM, 2014.

Peralta, Álvaro; Pistacchio, Enzo. Duro de matar, Santiago, Zig-Zag, 2014.

Rojas, Mauricio. "La evolución del Partido Socialista de Chile durante la primera parte de la dictadura (1973 - 1979)". Divergencia, número 5, Santiago, Taller de Historia Política, 2014.

Salazar, Gabriel. Conversaciones con Carlos Altamirano. Memorias Críticas, Santiago, Ediciones Debate, 2010.

Sartori, Giovanni. Partidos y sistemas de partidos, Madrid, Alianza, 2005.

Valle, Jorge y Díaz, José Díaz. Federación de la Juventud Socialista. Apuntes históricos 1935 1973, Santiago de Chile, Cuadernos Documentas, 1987.

Yocelevzky, Ricardo. "El partido socialista de Chile bajo la dictadura militar", Foro internacional, volumen 27, número 1, Ciudad de México, El Colegio de México, 1986.

Documentos de partido sin referencia a revistas ni boletines: 
Informe de la Comisión política al Pleno del Comité Central de la Juventud Socialista. Presentado por el Secretario General de la JS, Carlos Lorca Tobar. 4 de junio de 1972. www.socialismochileno.org

Secretariado interior Partido Socialista de Chile, "Al calor de la lucha contra el fascismo, construir la fuerza dirigente del pueblo para asegurar la victoria", marzo de 1974, www.socialismochileno.org

Resoluciones del Pleno del Comité Central, abril de 1979. Partido Socialista de Chile, Secretariado Exterior, Comité Central. www.socialismo-chileno.org

Acuerdos y conclusiones para la unidad del Partido Socialista de Chile. 19 de abril de 1983. www.socialismo-chileno.org

"Notas sobre el documento del CC, marzo de 1974", documento fechado en abril de 1974 y firmado por "Juan Cristóbal", seudónimo de Adonis Sepúlveda. En compilado de documentos: "Problemas del Partido Socialista de Chile posteriores al golpe militar (1974 - 1981)", México DF, 1984. www.socialismo-chileno.org

Resoluciones Políticas del V Pleno Nacional Clandestino del Partido Socialista de Chile. Agosto, 1984. www.socialismo-chileno.org

Partido Socialista de Chile, "Resoluciones del 24 congreso del Partido Socialista de Chile", agosto 1985, http://www.socialismo-chileno.org/ .

Listado de entrevistados citados.

\begin{tabular}{|c|c|c|c|c|}
\hline Nombre & $\begin{array}{l}\text { Trayectoria de pertenencia a } \\
\text { corrientes hasta el momento } \\
\text { de la entrevista. }\end{array}$ & $\begin{array}{l}\text { Cargos } \\
\text { destacados } \\
\text { en el período } \\
\text { estudiado. }\end{array}$ & $\begin{array}{l}\text { Año de } \\
\text { nacimiento }\end{array}$ & $\begin{array}{l}\text { Año de } \\
\text { entrevista. }\end{array}$ \\
\hline 1.- Ernesto Águila & $\begin{array}{l}\text { Ps Almeyda, Tercerismo, } \\
\text { Izquierda Socialista. }\end{array}$ & $\begin{array}{l}\text { Miembro de } \\
\text { la CNJ. } \\
\text { Presidente } \\
\text { de la UJS. }\end{array}$ & 1962 & $\begin{array}{ll}2012- \\
2016\end{array}$ \\
\hline 2.- Jaime Fuentealba & $\begin{array}{l}\text { Ps Almeyda, Generacional, La } \\
\text { Franja, Nueva Izquierda y } \\
\text { Colectivo de } \\
\text { Socialista. }\end{array}$ & $\begin{array}{l}\text { Presidente } \\
\text { de la JS } \\
1991 .\end{array}$ & 1965 & 2012 \\
\hline 3.- Ricardo Solari & Ps Almeyda- Tercerismo. & $\begin{array}{l}\text { Miembro de } \\
\text { la dirección } \\
\text { clandestina } \\
\text { del PS }\end{array}$ & 1954 & 2012 \\
\hline $\begin{array}{l}\text { 4.- Jaime Pérez de } \\
\text { Arce }\end{array}$ & Ps Almeyda- Tercerismo. & $\begin{array}{l}\text { Secretario } \\
\text { General de } \\
\text { la JS en } \\
1986 .\end{array}$ & 1955 & 2012 \\
\hline 5.- Gonzalo Durán & $\begin{array}{l}\text { Almeydismo. } \\
\text { Colectivo de Identidad } \\
\text { Socialista. }\end{array}$ & $\begin{array}{l}\text { Secretario } \\
\text { Político de } \\
\text { la Dirección } \\
\text { Regional de } \\
\text { Enseñanza } \\
\text { en la JS. } \\
\text { Miembro } \\
\text { del Comité } \\
\text { Central de } \\
\text { la JS en }\end{array}$ & 1968 & 2012 \\
\hline
\end{tabular}




\begin{tabular}{|c|c|c|c|c|}
\hline & & $\begin{array}{l}\text { segunda } \\
\text { mitad de los } \\
\text { años } 80 \text {. }\end{array}$ & & \\
\hline 6.- Enrique Acosta & $\begin{array}{l}\text { PS Núñez, } \\
\text { Socialista }\end{array}$ & & 1959 & 2012 \\
\hline 7.- Paulina Veloso & Almeydismo. Tercerismo. & & 1957 & 2012 \\
\hline 8.- Arturo Barrios & $\begin{array}{lr}\begin{array}{l}\text { Generacional, La } \\
\text { Nueva Izquierda, }\end{array} \text { Nuevo } \\
\text { Socialismo, Grandes } \\
\text { Alamedas, y finalmente } \\
\text { "Nuestra Revolución". }\end{array}$ & $\begin{array}{l}\text { Presidente } \\
\text { de la FECH } \\
1992 .\end{array}$ & 1967 & 2012 \\
\hline 9.- Germán Correa & Almeydismo. Tercerismo & $\begin{array}{l}\text { Miembro } \\
\text { dirección } \\
\text { clandestina } \\
\text { del PS. }\end{array}$ & 1939 & 2016 \\
\hline 10.- Eduardo Gutiérrez & $\begin{array}{l}\text { Almeydismo. Comandantes. } \\
\text { Retorna por breve tiempo al } \\
\text { PS a fines de la década de } \\
1990 \text { y hoy es independiente. }\end{array}$ & $\begin{array}{l}\text { Miembro } \\
\text { dirección } \\
\text { clandestina } \\
\text { del PS }\end{array}$ & 1951 & 2016 \\
\hline
\end{tabular}

